\title{
Fixed Effects and Post-Treatment Bias in Legacy Studies *
}

\author{
Jonathan Homola \\ Miguel M. Pereira \\ Rice University \\ homola@rice.edu \\ Washington University in St. Louis \\ m.pereira@wustl. edu \\ Margit Tavits \\ Washington University in St. Louis \\ tavits@wustl.edu
}

June 8, 2020

\begin{abstract}
A growing literature examines how historical institutions influence contemporary political attitudes and behavior. Recent work has argued that these studies need to properly account for spatial heterogeneity by incorporating regional fixed effects. Here, we discuss the theoretical and empirical obstacles that have to be addressed to properly incorporate fixed effects in legacy studies. We illustrate our arguments using Pepinsky et al.'s (2020) reassessment of a recent study on the long-term effects of concentration camps in Germany (Homola et al. 2020). We show that Pepinsky et al. incorporate fixed effects incorrectly and, as a result, their analysis suffers from post-treatment bias. We further demonstrate that results from the original article remain substantively the same when we incorporate regional fixed effects correctly. Finally, simulations reveal that camp proximity consistently outperforms spatially correlated noise in this specific study.
\end{abstract}

*We would like to thank Avidit Acharya, Volha Charnysh, Vicky Fouka, Soeren Henn, Florian Hollenbach, Connor Huff, Chris Lucas, Noam Lupu, Jacob Montgomery, Leonid Peisakhin, Arturas Rozenas, Michelle Torres, and Rick Wilson for comments and helpful discussions about earlier versions of the paper. 
A prominent set of studies in political science shows that long-deceased coercive institutions often continue to influence contemporary political attitudes and behavior (e.g., Acharya et al. 2016a; Charnysh and Finkel 2017; Lupu and Peisakhin 2017; Mazumder 2018; Nunn and Watchekon 2011; Rozenas and Zhukov 2019; Rozenas et al. 2017; Voigtländer and Voth 2012; see also Simpser et al. 2018 for a review). Reliably establishing legacy effects is challenging. It requires making robust causal inferences over a very long time span during which the treatment could have affected not only the outcome but also other variables relevant for the analysis. To deal with this unique challenge, most legacy studies are carefully designed, conduct a diverse set of analyses, and explicitly address post-treatment bias by employing appropriate methods such as the sequential g-estimator.

Building upon the analytical strategies established in the legacies literature, our recent study (Homola et al. 2020 - HPT) explores the long-term political consequences of the Third Reich. The results show that current-day political intolerance, xenophobia, and voting for radical right-wing parties are associated with proximity to former Nazi concentration camps in Germany. This conclusion relies on a series of analyses using election results and data from two different surveys to measure contemporary attitudes and behavior. Additional analyses demonstrate that pre-war attitudes did not drive camp locations, and provide preliminary evidence for the mechanisms of attitude change in response to camp proximity and the transmission of these attitudes over time.

Pepinsky et al. (2020 - PGZ) re-examine our paper and argue that it ignores "Germany's federal structure as an important source of variation in out-group attitudes" (p. 5). As a consequence, the analysis "risks picking up these enduring regional differences by accident" (p. 6). To overcome this perceived shortcoming, PGZ add state-level fixed effects to our OLS models and to both stages of the g-estimator models, and find that the distance measure is no longer a statistically reliable predictor of intolerance (p. 14-17). ${ }^{1}$ HPT's analysis accounts for regional heterogeneity by including controls such as the local-level share of

\footnotetext{
${ }^{1}$ PGZ's discussion and analysis includes important inconsistencies. To help the reader better follow our original study and its criticism by PGZ, we record some of these inconsistencies in SI 8.
} 
unemployment and foreigners, level of urbanity, or a dummy for East vs. West Germany. While we considered these solutions sufficient and did not find a theoretical motivation to include state fixed effects, other scholars operating in good faith might find doing so important for theoretical or empirical reasons.

However, including fixed effects in papers on the long-term legacies of historical events is not straightforward and scholars interested in doing so must overcome two main obstacles, one theoretical, and one empirical. Informed by theory, scholars first need to decide what type of confounding the fixed effects are supposed to correct. This determines which regional units to control for: the pre- or post-treatment ones. Throughout history, borders are commonly drawn and redrawn, often with attributes of the population in mind, and this means that pre- and post-treatment regional units can be very different. In the case of Germany, for instance, state borders were largely redrawn after 1945, and in some instances with the direct participation of citizens, through referendums. The second obstacle entails a careful examination of the causal paths linking historical institutions and contemporary outcomes. Scholars need to pay special attention to issues of post-treatment bias and adjust their empirical approach accordingly. Depending on whether the regional units are pre- or post-treatment shapes which specification is correct, and in turn, whether or not the results are biased.

In the remainder of this note, we first highlight the challenges of including fixed effects in efforts to estimate the impact of historical events with survey data. Most importantly - as is well documented in the statistical and substantive literature - their inclusion can dramatically reduce statistical power, increase sample variance, and spoil the representativeness of the data. Scholars are therefore well advised to carefully weigh the inclusion of fixed effects against potential alternative modeling choices. Next, we use PGZ's analysis to illustrate that the inclusion of fixed effects can also lead to post-treatment bias. We show that PGZ failed to overcome both of the obstacles for the proper inclusion of fixed effects listed above. As a result, they use contemporary (i.e., post-treatment) state fixed effects rather 
than the pre-treatment Weimar-era ones, and also incorrectly specify their empirical models. Both decisions contribute to post-treatment bias in their analysis. Fixing these issues by either (1) correctly specifying the contemporary states as post-treatment variables, (2) using pre-war states, or (3) combining these two approaches corroborates the original results in HPT. Finally, to assess the robustness of the findings to spatial correlation, we replicate the analysis in HPT replacing the geographic variable with spatially correlated noise (Kelly 2019). The simulations suggest that camp proximity consistently outperforms spatial noise as an explanatory variable. We conclude by highlighting the need for careful theoretical and empirical considerations in legacy studies to be able to make the correct modeling choices in this challenging field.

\section{Challenges of using fixed effects with survey data}

Using unit fixed effects is a common way to control for unobserved heterogeneity across regions or other sub-national units. This is particularly true in studies that use population data (e.g., Bruckmeier et al. (2013) and Hoerner et al. (2019) use state fixed effects with population data), or survey data that has a large number of respondents from each subnational unit (e.g., Acharya et al. (2016a) and Schündeln (2014) use state fixed effects with survey data that are representative at the state level).

Most survey data, however, are based on relatively small samples and only designed to be representative at the national level. In this context, the inclusion of regional fixed effects raises two specific concerns: underpowered analyses and unrepresentative subsamples. Take the two surveys in HPT: the European Values Survey (EVS) and the German General Social Survey (ALLBUS). In the EVS, for example, the number of observations per state ranges from only 17 to 314 (with a median of 118.5) in the OLS specifications, and from 1 to 219 (with a median of 71.5) in the g-estimator specifications (see Tables SI4.1-SI4.3 for more details). 
In addition to the small number of observations per state, it is important to note that surveys commonly sample their respondents from only a few specific primary sampling units (PSUs) within each state and do not take random samples at the state level. As a consequence, variation in the main predictor of interest - camp proximity - is limited within each state. For five of Germany's 16 contemporary states, the EVS data only include respondents with four or fewer different camp distance measures. Only five states have a range of distances that covers half or more of the full distance scale (Table SI4.1 describes the number of primary sampling units by contemporary state). In other words, more than half of the states have a limited range of values for the main explanatory variable. These issues are not unique to the surveys used in HPT and apply to most survey data designed to be representative at the national level.

Including state fixed effects essentially amounts to a within-state analysis. ${ }^{2}$ With survey data that have only a small number of observations and limited variation within each state such an attempt quickly becomes problematic because it dramatically reduces statistical power and raises concerns about the reliability of the analyses (Lax and Phillips 2009; Levendusky et al. 2008). ${ }^{3}$ This is particularly concerning in studies like HPT, where the treatment is assigned spatially and survey respondents are drawn in a clustered fashion from a limited number of locations, leading to minimal levels of within-state variation in the treatment. Such analyses may easily pick up arbitrary and spurious effects and produce results that are unlikely to generalize to new (i.e., out-of-sample) data (Gelman and Hill 2006; Hawkins 2004). ${ }^{4}$ In short, analyses with samples like those of EVS or ALLBUS are

\footnotetext{
${ }^{2}$ In fact, for much of their re-analysis of HPT, PGZ are either running separate analyses by state (p. 11-14) or explicitly modeling separate effects of distance for each state through interactions and random slopes (p. 19-26).

${ }^{3}$ Recent efforts to develop subnational estimates of public opinion build upon a similar measurement concern (e.g., Park et al. 2004; Selb and Munzert 2011). However, the solutions advanced in this literature do not apply to HPT since they are meant to produce aggregate (instead of individual-level) measures of public opinion.

${ }^{4}$ Moreover, Clark and Linzer (2015), Middleton et al. (2016), and Plümper and Troeger (2019) show that adding group fixed effects in studies like HPT can actually lead to bias instead of overcoming it. In fact, they explicitly caution against the "arbitrary use of fixed effects for groups in non-experimental studies" (Middleton et al. 2016: 309).
} 
underpowered to make claims about within-state variation (see also Blaydes 2006). ${ }^{5}$

Given these concerns, many scholars refrain from using regional fixed effects with survey data and instead try to account for regional heterogeneity by including a series of variables that measure theoretically important variation at the regional level (e.g., HPT; Charron et al. 2017; Dancygier and Saunders 2006; Maxwell 2019; Mitts 2019; Rueda and Stegmueller 2016; Ziblatt et al. 2020). Other scholars may have strong theoretical or empirical reasons to include fixed effects despite these concerns. However, correctly including fixed effects as part of an effort to estimate the impact of historical events poses additional challenges, as incorrect choices about regional units (pre- vs. post-treatment ones) and model specification can lead to post-treatment bias. We illustrate this in the next section using PGZ's reanalysis of HPT as an example.

\section{Post-treatment bias}

The causes and consequences of post-treatment bias (and how to avoid it) have recently received considerable attention in the discipline (Acharya et al. 2016b; Aronow et al. 2019; Coppock 2019; Gerber and Green 2012: chapter 4; Montgomery et al. 2018). Post-treatment bias occurs when an analysis conditions on a variable that is directly or indirectly affected by the treatment and also shares a common cause with the outcome of interest. ${ }^{6}$ For example, in a simple OLS regression of an outcome $Y$ on treatment $A$, we cannot include a variable $M$ that shares an unmeasured common cause $u$ with the outcome $Y$ and is affected by the treatment $A$. Post-treatment bias is especially problematic because without very strong

\footnotetext{
${ }^{5}$ Relatedly, regional fixed effects can spoil the representativeness of survey data. This is problematic if the unrepresentative patterns are correlated with the outcome and/or predictor, and also because it minimizes variation in the treatment variable. Both EVS and ALLBUS are designed with this concern in mind, oversampling respondents in East Germany to allow "for independent analyses of both parts of Germany" (EVS 2010: 22; ALLBUS 2017). Consistent with this sampling strategy, the original analyses in HPT include an East/West fixed effect. The same is not true for each of the 16 German states.

${ }^{6} \mathrm{It}$ is important to stress that post-treatment bias can occur even when the treatment and the posttreatment variables are only indirectly related (Montgomery et al. 2018). PGZ (p. 27) mischaracterize this issue to defend their empirical strategy: "camp locations did not directly cause Länder borders (so they are not post-treatment variables)."
} 
assumptions, it is impossible to know how it affects our estimates of interest. Neither the direction nor the magnitude of the bias are possible to anticipate (Elwert and Winship 2014; Montgomery et al. 2018; Rosenbaum 1984).

To overcome these difficulties in settings where we have strong theoretical reasons to include variables that are measured post-treatment, more complex modeling strategies and extra sets of assumptions are necessary. The sequential g-estimator is one such approach. It allows us to incorporate not only pre-treatment variables, but also post-treatment confounders and mediators without incurring post-treatment bias.

Figure 1: Directed acyclic graph illustrating the g-estimator

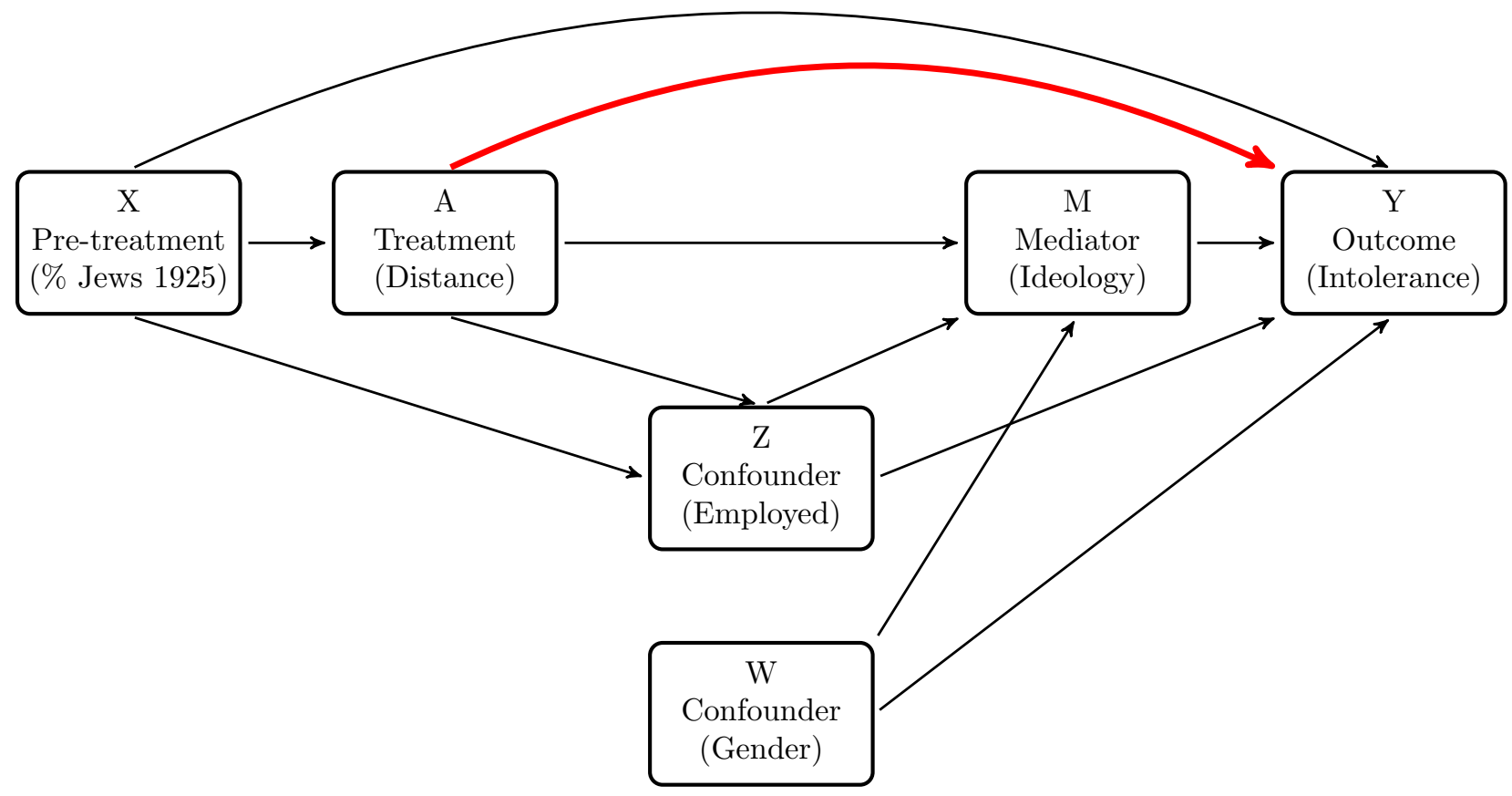

Note: The bold red line represents the controlled direct effect. Pre-treatment (i.e., Weimar-era) state-level fixed effects can be included as pre-treatment variables $X$. Post-treatment (i.e., contemporary) state-level fixed effects can be included as post-treatment confounders $Z$ or $W$.

Figure 1 shows a causal relationship between different types of variables of interest, where the flow of causality runs from left to right. We have a set of pre-treatment variables $X$, the treatment variable $A$, a mediator $M$, and the outcome of interest $Y$. In addition, there 
are two types of confounders: $Z$, which is affected by the pre-treatment variables and the treatment, and $W$, which is not. Both $Z$ and $W$ confound the relationship between the mediator and the outcome.

In HPT, we use variables like a district's share of Jews in 1925 or unemployment rate in 1933 as pre-treatment variables $X$. Our treatment $A$ is the distance of a survey respondent (or area in the analyses with electoral data) to the closest former concentration camp, and the outcome of interest $Y$ is captured by different indicators of out-group intolerance. We can think of our control variables, such as a respondent's employment status, as confounders $Z$ that are likely to be affected by $X$ and $A$. Other controls, such as age or gender, can be thought of as confounders $W$ that are unlikely to be affected by $X$ and $A$. Similarly, we can think of an individual's ideology as a mediator $M$.

To analyze this data structure, HPT employ the sequential g-estimator (Acharya et al. 2016a; 2016b; Robins et al 1992; Vansteelandt 2009). In broad terms, g-estimation starts by estimating a model with both pre-treatment and post-treatment covariates (first stage). Next, it recalculates the outcome variable by removing from it the effects of the mediating variables of interest. Finally, it estimates the effect of the treatment on this "demediated" outcome (second stage). Post-treatment bias is avoided by excluding posttreatment variables from the second stage. To account for the added uncertainty of the two-step procedure, bootstrapped standard errors are usually reported.

PGZ introduce state-level fixed effects into this setup. While they briefly discuss potential post-treatment problems (p. 7), they do not draw the right conclusions from it for their modeling strategy. More specifically, they use present-day state-level fixed effects as pretreatment variables, including them in the OLS specification and in both stages of the g-estimator. However, contemporary states are clearly post-treatment and induce posttreatment bias. In the following section we explain these concerns in more detail. 


\section{Contemporary state-level FE are post-treatment variables}

A key question one has to answer for any potential variable to be included in a causal analysis is whether it is measured pre-treatment or post-treatment. In the case of HPT's study, the treatment is the activity of the camps in Germany, operating between 1933 and 1945. Statelevel fixed effects could now theoretically play two different roles. Going back to Figure 1, we could include fixed effects as pre-treatment variables $X$ to account for potential regional heterogeneity in treatment assignment $(A)$, in the confounders $(Z)$, and the outcomes $(Y)$. Alternatively, we could include fixed effects as post-treatment confounders $Z$ or $W$ if we expect them to confound the relationship between the mediator and the outcome. The statelevel fixed effects PGZ are using for their main analysis reflect the states of contemporary Germany. Figure 2 illustrates why current-day states are post-treatment constructs in the context of our study.

Of the 16 German states that exist today, only six existed before the first concentration camp was built. And even these six regions changed considerably: for two of them (Hamburg and Hesse), less than $50 \%$ of their current territory overlaps with their Weimar-era territory, and only Bavaria remains largely unchanged (although the contemporary state no longer includes the Rhenish Palatinate region). ${ }^{7}$ In Western Germany, the collection of states as we know them today has only existed since 1957 when the Saar Protectorate rejoined the Federal Republic as the Saarland. In the GDR, in turn, the states were abolished and only reinstated with new borders in 1990 upon the reunification.

Hence, the "distinct identities and political cultures" and "unsynchronized policy environments" that PGZ (p. 5) capture with their fixed effects were likely formed over time since the 1950s. ${ }^{8}$ In other words, multiple decades passed between the construction of the con-

\footnotetext{
${ }^{7}$ The proportion of territory in these six states overlapping with their Weimar-era counterparts is: $99.2 \%$ (Bavaria), 64.5\% (Bremen), 39.0\% (Hamburg), 29.7\% (Hesse), 79.2\% (Saxony), and 70.0\% (Thuringia). PGZ mention that Saxony and Thuringia "remain almost unchanged" (p. 28). While this is true when we look at the snapshots in 1932 and today, it ignores that once these states became part of the GDR, they were abolished and divided up into districts (Bezirke) in 1952. This example illustrates the fluidity of regional borders over this period.

${ }^{8}$ Needless to say, there are regional differences across the country that have deeper roots (e.g., Sackmann
} 
Figure 2: State borders in the Weimar Republic (1932) and in contemporary Germany

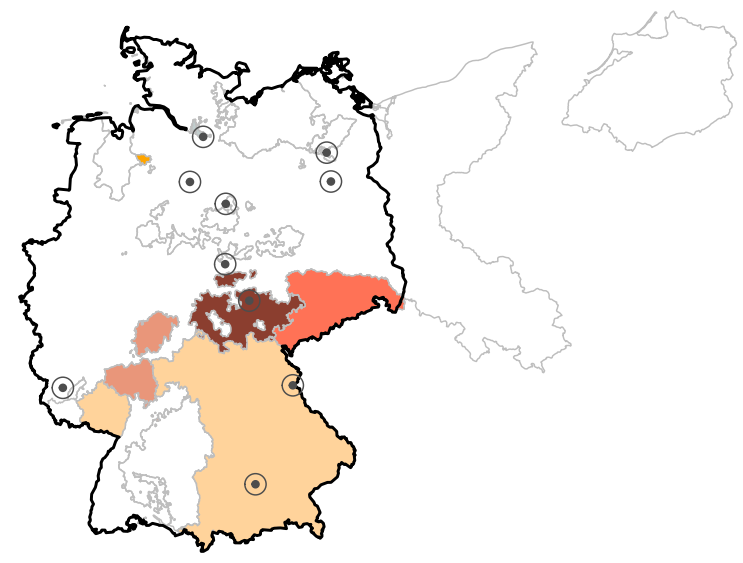

(a) Weimar Republic states

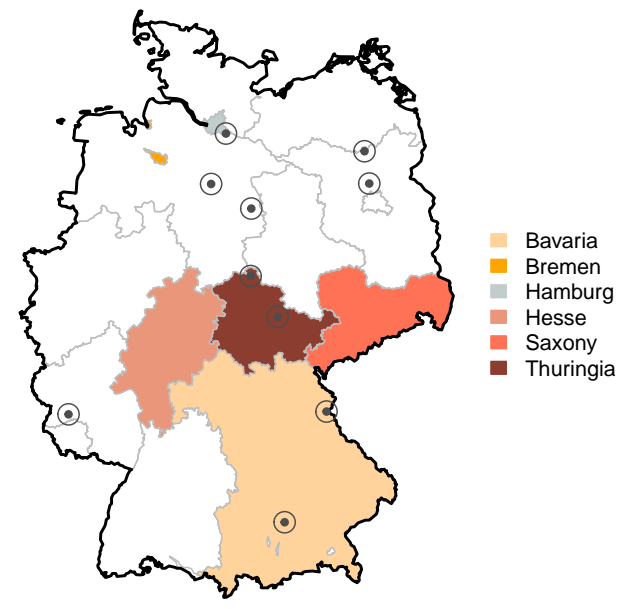

(b) Contemporary states

Note: Panels (a) and (b) describe the state borders in 1932, the year before the first German concentration camp was created, and in contemporary Germany, respectively. In each panel, gray lines indicate the state borders and the dark line corresponds to the current border of Germany. The shaded states in each panel correspond to the six states from the Weimar period that still exist today.

centration camps and the creation of the German states we know today. As a consequence, contemporary state-level fixed effects - and any regional heterogeneity captured by them are measured post-treatment. Referring back to Figure 1, this means that, contrary to the PGZ approach, these fixed effects should not be considered as pre-treatment variables $X$. Instead, they should be treated as confounders $Z$ or $W$. We will do so in the next section and demonstrate that our original results hold when fixed effects are used appropriately.

In practice, by treating the contemporary state fixed effects as pre-treatment variables $X$, PGZ are trying to predict the past with the present. As Figure 1 indicates, pre-treatment variables are used to explain the treatment, the outcome of interest, and potential confounders. By introducing contemporary state fixed effects, PGZ are trying to explain the location of concentration camps in the 1930s and 1940s with states that were only formed decades later - something that simply does not make sense theoretically.

and Häußermann 1994). However, given the drastic changes in state borders over time, it would be hard to argue that these differences could be properly captured by contemporary state borders. 


\section{Post-treatment FE lead to post-treatment bias}

In addition to these theoretical issues, PGZ's empirical approach induces post-treatment bias. In very simple terms, the state fixed effects will lead to bias if they pick up any otherwise unobserved heterogeneity that is affected by the treatment. PGZ argue that this is unlikely - an assessment that is hard to agree with either substantively or theoretically, and impossible to demonstrate. Substantively, we will briefly discuss three ways in which contemporary state fixed effects are likely to induce post-treatment bias.

First, after World War II, southwestern Germany initially consisted of three states: Baden, Württemberg-Hohenzollern, and Württemberg-Baden. The Württemberg-Baden government wanted to unify all three into a single state, but Baden was against it. The new Basic Law from 1949 contained a specific article, which clarified that if the states could not come to an agreement, a referendum would be held. This referendum took place on December 9, 1951 and ultimately resulted in a merger of the three states into the new state of Baden-Württemberg. ${ }^{9}$ The political discussion in the run-up to the referendum focused on economic and administrative issues but also on out-group resentment, including anti-Baden attitudes and religious factions (Weber and Häuser 2008). In other words, in this specific instance citizens themselves determined the shape of their states. If the concentration camps affected people's beliefs during the Third Reich, as we argue, and these same people decided the shape of states created post-war, contemporary state fixed effects can induce bias.

Second, PGZ mention one specific variation across states that their fixed effects capture: the existence of "substantial variations in school curricula" (p. 6). While all state curricula include the discussion of the Nazi regime, importantly for our purposes, there is systematic variation in whether or not students visit a concentration camp. This variation, however, is likely post-treatment. Since camp visits are not mandatory, schools are more likely to organize a visit if there is a camp close by; some states even subsidize camp visits if they happen within the same state (Rathenow and Weber 1995). Therefore, policies determined

\footnotetext{
${ }^{9}$ https://www.lpb-bw.de/entstehung-baden-wuerttembergs
} 
by today's states affect the likelihood that students will visit a camp. Contemporary state fixed effects would pick up these state-level differences and induce post-treatment bias.

Finally, on a more abstract level, we know that not every state has the same number of camps. For example, Brandenburg and Thuringia each have two camps in our analysis although they are among the smallest states in Germany. On the other hand, BadenWürttemberg and North Rhine-Westphalia are two of the largest states but do not have any camps. If we assume that the camps had any effect at all on their surrounding areas, and we know that some small states have multiple camps whereas some large states have no camps, then these camp effects are necessarily leading to state-level differences that are (a) clearly

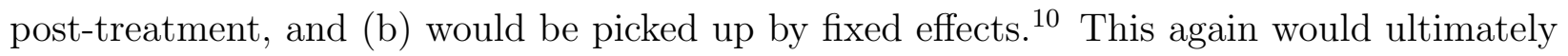
lead to post-treatment bias.

These examples use qualitative knowledge of the case to show that the inclusion of contemporary state fixed effects is likely to induce post-treatment bias. In the Appendix SI 2, we make the same point formally using PGZ's notation and assumptions, while also showing that their definition of potential post-treatment bias is incomplete (see fn. 6 , above).

\section{How to avoid post-treatment bias}

The above discussion helps illustrate two obstacles that a scholar needs to overcome in order to correctly account for regional heterogeneity in historical analysis. The first obstacle is theoretical: the scholar needs to clarify what type of confounding the fixed effects are supposed to account for. PGZ do not provide a clear theoretical motivation for their choices. The authors claim that Germany's federal structure is "an important source of variation in out-group attitudes," and that states have "distinct identities and political cultures," "unsynchronized policy environments," different historical origins, and "substantial variations in school curricula" (p. 5-6). However, why and how these factors might be affecting treat-

\footnotetext{
${ }^{10}$ It seems fair to assume that the camps had some effect on their surrounding areas. In line with this, PGZ themselves conclude that areas closer to camps vote differently in elections than areas farther away (p. 32-34).
} 
ment assignment or confounding the relationship between distance and out-group attitudes remains unclear.

In contrast, consider Acharya et al. (2016a: 626), who provide a clear argument for including state fixed effects in their analysis: to "address the possibility that states adopted different policies that could have influenced slave shares in 1860 and could affect [their] outcome variables in ways unrelated to slavery." In the case of concentration camps, a similar argument would discuss a potential concern that Weimar-era states adopted different policies that could have influenced the location of concentration camps. If one made such an argument, it would become clear that Weimar-era states (not current-day states) should be included in the analysis. In short, clear theory is needed because it helps the scholar identify the correct regional units for fixed effects.

The second obstacle to account for regional heterogeneity is methodological and requires that the scholar fully understands the issue of post-treatment bias and how to appropriately account for it in the empirical model specification. First, in the OLS specifications with camp proximity predicting contemporary attitudes and behavior, contemporary states cannot be included without risking post-treatment bias. Second, the sequential g-estimator provides a solution to this issue, which is why it has become the workhorse model in legacy studies. However, it needs to be implemented correctly: either modeling contemporary state fixed effects as post-treatment variables (only in the first stage), or instead introducing pretreatment state fixed effects in both stages of the analysis. Violating these specifications can lead to biased estimates.

In the next section we show how to overcome these two obstacles by either (1) correctly specifying contemporary states as post-treatment variables, (2) using pre-treatment state fixed effects, or (3) combining both approaches. Once regional heterogeneity is appropriately included in the analyses, the original results in HPT continue to hold. That said, we reiterate that concerns regarding the use of fixed effects with survey data remain. The inclusion of fixed effects in the EVS models leads to underpowered analyses, and therefore the results 
should be interpreted with caution.

\section{Three solutions to account for regional heterogeneity}

Let us start with the first solution - correctly accounting for post-treatment variables. Consider again the causal relationship in Figure 1. PGZ treat the contemporary state fixed effects as pre-treatment variables $X$. We explained above that this does not make sense theoretically (i.e., trying to predict the past with the present) and described specific ways in which it induces post-treatment bias. However, g-estimation does provide a way to overcome these flaws. Instead of treating the fixed effects as pre-treatment variables, we consider them to be post-treatment confounders $W$ or $Z$. This means assuming that contemporary states are confounding the relationship between the mediator (e.g., ideology) and the outcome (e.g., out-group intolerance). Theoretically, this makes intuitive sense and is in line with the potential confounding effects of state heterogeneity that PGZ discuss ("unsynchronized policy environments," "substantial variations in school curricula"). In HPT, we adopt this same procedure to account for systematic differences between East and West Germany.

In terms of the actual estimation, this means that the fixed effects should appear in the first stage of the sequential g-estimator, but not in the second stage. Recall that the goal of the first stage is to accurately estimate the effect of the mediator on the outcome to successfully "de-mediate" the outcome before the second stage. The confounders $W$ or $Z$ (i.e., the contemporary state fixed effects) are only relevant for this part of the estimation and should not be included in the second stage. Instead, the second stage consists of "regressing this demediated outcome on the treatment and the pre-treatment confounders" (Acharya et al. 2016b: 521), as explicitly stated in prior work on g-estimation in political science and epidemiology (Robins et al 1992; Vansteelandt 2009). ${ }^{11}$

As the second solution to avoid post-treatment bias, we replace contemporary state fixed effects with pre-treatment state fixed effects. Specifically, we use Germany's administrative

\footnotetext{
${ }^{11}$ PGZ's implementation of the g-estimator includes a number of inconsistencies, which we discuss in SI 8.
} 
map from 1932 as seen in Figure 2 to identify the corresponding Weimar-era state for each present-day geographic location. ${ }^{12}$ We chose 1932 because it is the year before the first German camp was created (Dachau, March 1933). Theoretically, the use of the Weimar states means that we are now working with true pre-treatment variables $X$ (cf. Figure 1 ). The Weimar states might affect camp locations (our treatment) through their policy environment or other unobserved factors that our other pre-treatment variables did not capture. They can also affect some of the contemporary confounders $(Z)$ and our outcome variables $(Y)$. Empirically, it means that the Weimar state fixed effects can now be included in both stages of the g-estimator without inducing post-treatment bias. ${ }^{13}$

Finally, we combine both approaches by correctly specifying contemporary states as posttreatment variables and only using them in the first stage and at the same time using Weimarera state fixed effects in both stages of the g-estimator. This third specification allows us to simultaneously account for historical regional differences that may explain camp location, and for any post-treatment confounder that varies systematically across contemporary states.

Matching contemporary geographical units with Weimar-era states is not straightforward. First, contemporary districts are not always contained within a single Weimar-era state. Second, the state of Saarland was not part of Weimar Germany. We therefore use three alternative methods to interpolate Weimar states: (1) matching each contemporary district to the Weimar state that overlaps with the district's geographical center (centroid interpolation), (2) using the same centroid interpolation but including Saarland respondents/districts as an additional Weimar state, and (3) matching each contemporary district to the Weimar state that overlaps with the largest share of its area (area interpolation). For parsimony reasons, the analyses reported below only include the first interpolation method. However, all three approaches lead to the same substantive conclusions, as reported in SI 3

\footnotetext{
${ }^{12}$ We rely on the same geodata as in HPT (MPIDR and CGG 2011).

${ }^{13}$ In our original analysis and the models we report below, we include multiple mediating variables. This could be stretching the limits of the g-estimation approach. As a robustness check, we therefore also replicated all models using only one contemporary variable as a mediator and specifying the others as confounders. Our main results remain unchanged and these new model specifications can be found in SI 5 .
} 
and SI $4 .^{14}$

Together, HPT, PGZ, and the current note provide an extensive list of models with different data sources and model specifications. To help the reader follow this collective effort, Table SI1.1 summarizes the different main specifications modeling the effect of camp proximity on contemporary outcomes.

\section{Results}

We replicate the main analyses in HPT, i.e., the results in Table 2 (EVS) and Table 4 (electoral data) while including (1) contemporary state-level fixed effects in the first stage of the g-estimator, (2) Weimar-era state-level fixed effects in both stages of the g-estimator, and (3) both contemporary states and Weimar-era states. ${ }^{15}$ The solutions advanced here to account for regional heterogeneity do not address our concerns regarding the use of fixed effects in survey data discussed above. The EVS models with fixed effects are underpowered and should be interpreted with caution (see SI 4 for the number of respondents and sampling units by state). Hence, we first present the results with the electoral data.

Figure 3 replicates the four columns of Table 4 in HPT. Each panel shows the controlled direct effect of camp proximity on support for radical right parties in 2017 for four different model specifications. The first coefficient (Baseline) is the effect that we report in our original paper. The second coefficient (Current state FEs in 1st stage) reports the results from the same model specification when we also include contemporary state fixed effects in the first stage of the g-estimator. The third coefficient ( Weimar state FEs) corresponds to the models including Weimar-era state fixed effects in both estimation stages. Finally, the last

\footnotetext{
${ }^{14} \mathrm{PGZ}$ also include an analysis with Weimar-era fixed effects. While the authors do not describe their exact interpolation strategy and use a map from 1925, the results reported are substantively similar to those we report here. PGZ then further split the analyses, treating Prussian internal provinces as separate states. As a result of this further geographical slicing, the effects of camp proximity are no longer reliable. We discuss these analyses in greater detail in SI 6, where we (a) explain that the decision to split Prussia into provinces appears arbitrary, atheoretical, and leads to an underpowered analysis, (b) point out that PGZ's coding of states and provinces features a clear mistake, and (c) show that when we include province-level fixed effects in the electoral analysis, our main findings remain unchanged.

${ }^{15}$ The analyses do not include ALLBUS data because access to the dataset requires an in-person visit to the GESIS facilities in Cologne, which are currently closed due to the coronavirus pandemic.
} 
Figure 3: The controlled direct effect of camp proximity on support for radical right parties in 2017, accounting for state-level heterogeneity

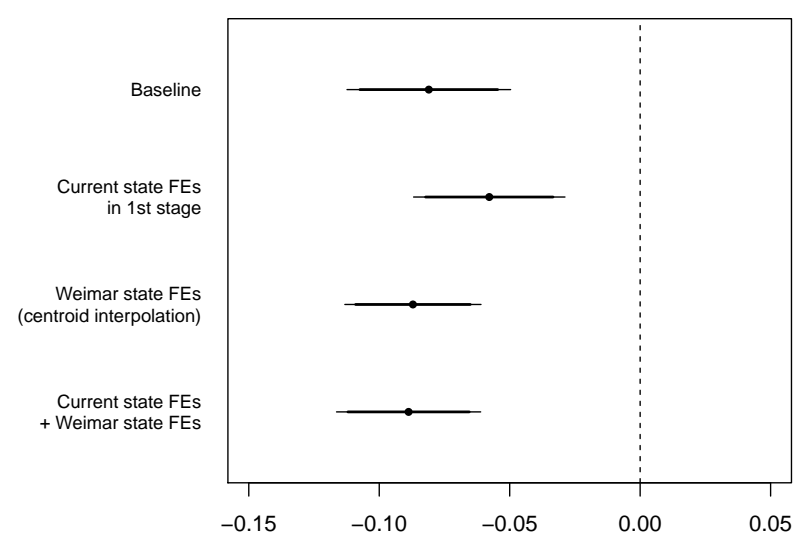

(a) AfD, full sample

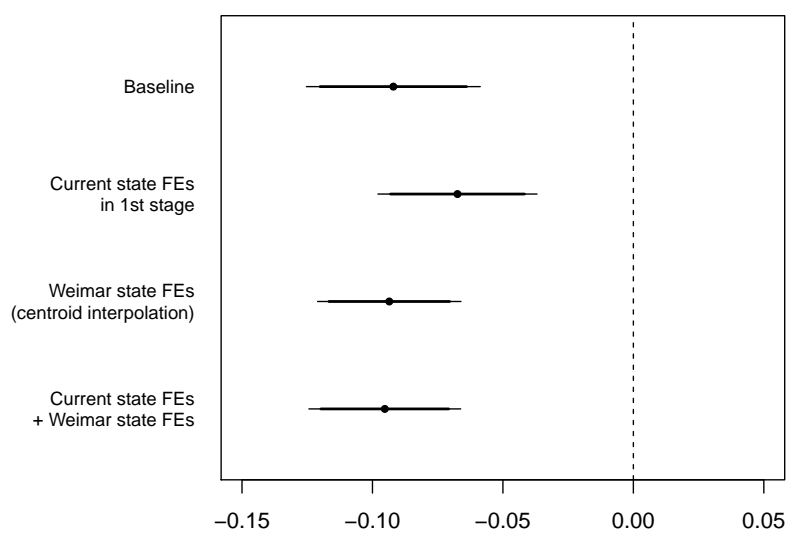

(c) AfD $+\mathrm{NPD}$, full sample

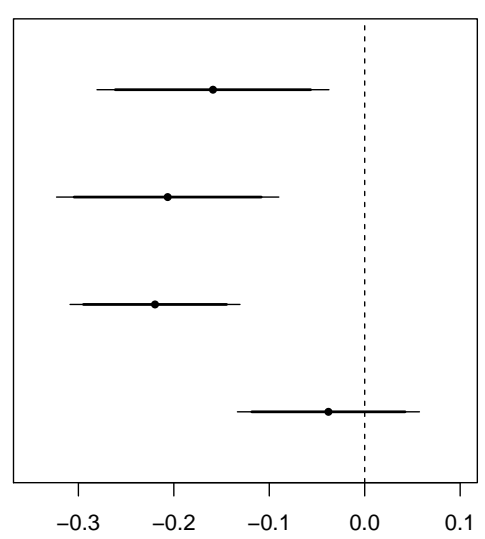

(b) AfD, $70 \mathrm{~km}$ radius

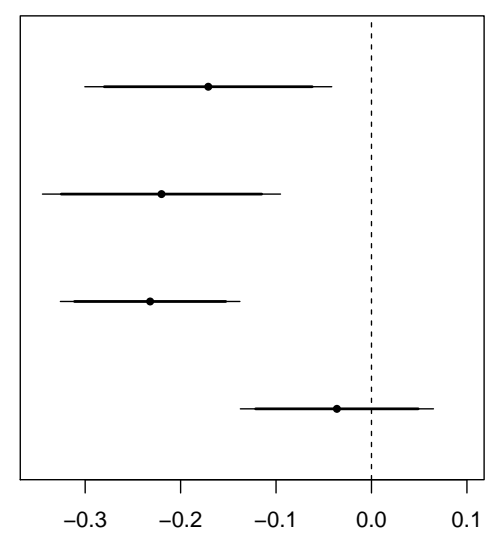

(d) $\mathrm{AfD}+\mathrm{NPD}, 70 \mathrm{~km}$ radius

Note: Plots depict estimates and 95/90\% confidence intervals from the sequential g-estimator for the controlled direct effects of distance to camps on support for radical right parties in 2017 (described in each panel label). Each estimate corresponds to a different model specification, described on the $y$-axis. The baseline specification corresponds to the results reported in Table 4 in Homola et al. (2020). Full model results for the remaining specifications in Tables SI3.1-SI3.3.

coefficient (Current state FEs + Weimar state FEs) corresponds to models simultaneously accounting for contemporary regional differences in the first stage, and including Weimar-era fixed effects in both stages.

The results show that our main conclusions are robust to the inclusion of state fixed effects. Across the different specifications, we see that the effect of distance is always negative and statistically reliable at conventional levels except for the models within a $70 \mathrm{~km}$ radius and 
with pre- and post-treatment regional fixed effects. ${ }^{16}$ We also do not observe any dramatic changes in the uncertainty of our estimates. In other words, Figure 3 suggests that when unobserved heterogeneity across German states is taken into account appropriately, the main findings we report in HPT remain unchanged.

The three panels in Figure 4 repeat this exercise for our EVS analysis. More specifically, each panel replicates the results in HPT, Table 2, Columns 2, 4, and 6, respectively, corresponding to a different outcome variable. ${ }^{17}$ We report the controlled direct effect of camp proximity for the same four model specifications as in Figure 3.

Figure 4: The controlled direct effect of camp proximity on outgroup intolerance, immigrant resentment, and support for far-right parties (EVS), accounting for state-level heterogeneity

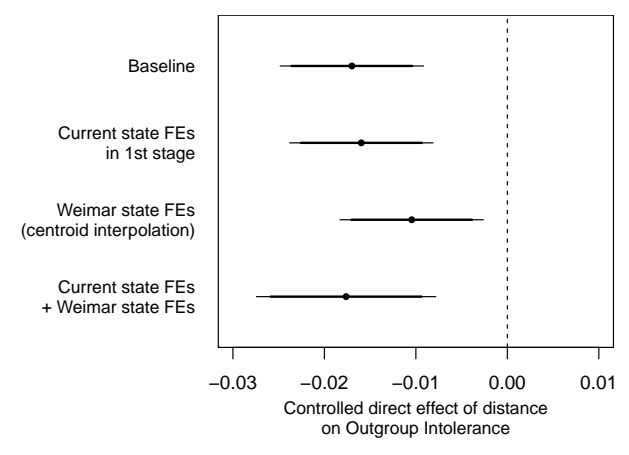

(a) Outgroup Intolerance

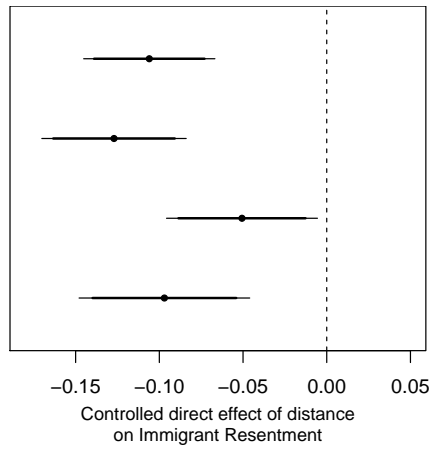

(b) Immigrant Resentment

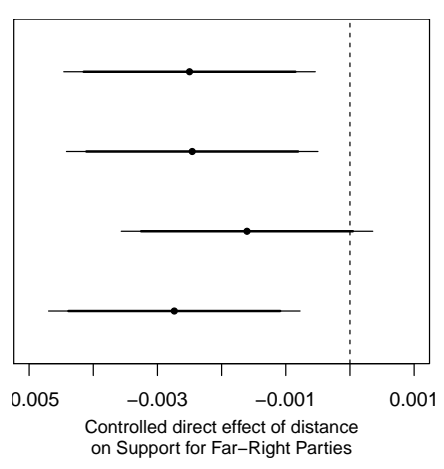

(c) Far-Right Support

Note: Plots depict estimates and 95/90\% confidence intervals from the sequential g-estimator for the controlled direct effects of distance to camps on contemporary attitudes (described in each panel label). Each estimate corresponds to a different model specification, described on the $y$-axis. The baseline specification corresponds to the results reported in Table 2 (Models 2, 4, and 6) in Homola et al. (2020). Full model results for the remaining specifications in Tables SI4.4-SI4.6.

Again we find support for our original conclusions. Across the different outcome variables and fixed effects specifications, we see that the effect of distance is always negative and reliable. When we introduce contemporary state fixed effects as post-treatment variables,

\footnotetext{
${ }^{16}$ We originally used the models focusing on a $70 \mathrm{~km}$ radius around each camp because they lead to samples that are better matched in terms of potential confounders. However, this approach includes dropping over $60 \%$ of all data points and consequently also implies a loss of variation in our treatment. The models with pre- and post-treatment fixed effects include a total of 33 regional fixed effects. Given the already restricted sample, it is therefore not surprising that the effects are no longer statistically reliable at conventional levels.

${ }^{17}$ Figure SI4.2, in the Appendix, replicates Columns 1, 3, and 5 from the same table, with OLS models. The same substantive results are obtained.
} 
our main results are virtually unchanged. When Weimar-era fixed effects are introduced, the effect sizes decrease slightly in all models. However, for both attitudinal measures (panels a and b) the effects remain statistically significant. Only the estimate for self-reported far-right support (panel c, coefficient 4) is no longer distinguishable from zero at conventional levels $(p$-value $=0.11)$, although the estimated effect is indistinguishable from the result obtained in the baseline model without state fixed effects. Given our general concerns about the use of state fixed effects in survey data, we interpret these results as reassuring. The totality of the evidence reveals that once we account for spatial heterogeneity in a way that avoids post-treatment bias, the results uncovered in HPT remain unchanged.

\section{Further investigating spatial correlation}

PGZ's effort is motivated in part by a recent study suggesting that a substantive portion of findings in the historical legacies literature is driven by spatial correlation (Kelly 2019). Although state-level heterogeneity - when properly incorporated in the analyses - does not explain the findings in HPT, spatial correlation may still play a role. Kelly proposes a two-step procedure to address this concern. First, Moran's autocorrelation index allows researchers to perform a diagnostic for potential misspecifications. Moran statistics provide a warning that nominal significance levels in a given model can be inflated due to spatial noise. Second, and to directly assess the robustness of the findings to spatial correlation, Kelly suggests reestimating the main models with spatially-correlated noise.

PGZ complete the first step of this procedure. The results suggest that significance levels may be inflated in HPT's analysis of the EVS data. In SI 9, we discuss why we believe Moran statistics are not appropriate for survey data with a clustered sampling frame, like EVS or ALLBUS. Consistent with our arguments, Kelly drops from his analysis the two studies that - like ours - rely on individual-level survey data. In this section, we push this effort further and conduct noise simulations to investigate the extent to which the main findings in 
HPT might be explained by spatial noise. Following Fouka and Voth (2020), we replace our geographic variable - Distance - with spatially correlated noise. The procedure consists of running 1,000 replications of the main models, each time with a different vector of spatially correlated random noise replacing Distance. A more detailed explanation and discussion can be found in SI 7.

Table 1: Explanatory power of the effect of spatial noise on contemporary outcomes

\begin{tabular}{lcc}
\hline & \multicolumn{2}{c}{ Correlation range } \\
\cline { 2 - 3 } & 3 degrees & 5 degrees \\
\hline Electoral data & & \\
AfD, full sample & $0.0 \%$ & $0.0 \%$ \\
AfD, 70km radius & $3.8 \%$ & $11.2 \%$ \\
AfD +NPD, full sample & $0.0 \%$ & $0.0 \%$ \\
AfD + NPD, 70km radius & $3.4 \%$ & $11.1 \%$ \\
EVS & & \\
Outgroup intolerance & $5.1 \%$ & $4.5 \%$ \\
Immigrant resentment & $0.4 \%$ & $0.9 \%$ \\
Far-right support & $1.1 \%$ & $1.1 \%$ \\
\hline
\end{tabular}

Note: Entries indicate how often spatial noise outperforms the original distance variable in explaining the different contemporary outcomes. For more details, see SI 7.

Table 1 presents the main results from this simulation exercise. More specifically, it shows the amount of times that spatial noise had more explanatory power than our original treatment variable across the 1,000 simulations. The results suggest that spatially-correlated noise rarely outperforms our Distance variable. As a reference point, in most of Kelly's replications of papers based on European data, the explanatory power of spatial noise outperformed the original predictor in $20-50 \%$ of all cases. None of our models approaches these numbers. Spatial noise outperformed camp proximity less than $5 \%$ of the time in 11 of the 14 sets of simulations performed. The only exceptions are the electoral data models within $70 \mathrm{~km}$ radii and a 5 degrees correlation range, where noise outperformed the predictor $11 \%$ of the time. The analyses suggest that camp proximity captures something more meaningful than mere spatial noise. 


\section{Conclusion}

Our goal with this research note is to contribute to the discussion of how to deal with regional heterogeneity in studies of historical legacies, especially when these rely on survey data. One common solution to account for regional heterogeneity is to include regional fixed effects in the analysis. Our note highlights the potential costs of doing so with survey data: their inclusion can dramatically reduce statistical power and lead to unreliable results.

We further discuss the specific challenges that the inclusion of fixed effects may pose in the context of legacy studies more generally, i.e., in work that tries to estimate the impact of historical events. We identify two obstacles that scholars need to overcome in order to avoid post-treatment bias when using fixed effects in studies of historical legacies. The first challenge is theoretical. Informed by theory, scholars need to decide what type of confounding the fixed effects are supposed to correct. This determines which regional units to control for: historical or current ones. In the context of legacy studies, this choice can be crucial and consequential given that borders are often redrawn throughout history, with features of the population in mind, potentially rendering current borders post-treatment. The second challenge entails making the correct modeling choices, e.g., correctly specifying the g-estimator to avoid post-treatment bias. The type of regional units used (pre-treatment or post-treatment) defines how they can be incorporated in the analysis and, in turn, whether the results are biased.

We show that these obstacles are real and consequential using the example of PGZ's criticism of a recent legacy study by HPT. Unfortunately, PGZ failed to overcome both of the obstacles listed above, which led to post-treatment bias in their analysis. Properly introducing regional fixed effects in HPT's original analysis - without inducing post-treatment bias - shows that PGZ's criticism of HPT is unwarranted. Finally, we assess the robustness of the findings in HPT to spatial correlation. By replacing our geographic variable with spatially-correlated noise, we show that spatial correlation does not appear to be a relevant threat to inference in this specific context. 
Our note offers practical reminders about the problem of post-treatment bias and how to avoid it in historical analysis. With this, we contribute to the growing, important, and exciting field of legacy studies. The note also contributes to the broader discussion about fixed effects. We highlight that, while commonly used, the choice of whether or not to include fixed effects is not straightforward. It pays to pause and think whether fixed effects are warranted at all, and if yes, how to properly include them without introducing further bias into the analysis. Ultimately, we hope to highlight the important interplay of theory and empirics, especially in the inherently complicated assessment of the present-day consequences of events that took place multiple generations ago. 


\section{References}

Acharya, Avidit, Matthew Blackwell, and Maya Sen. 2016a. "The political legacy of American slavery." The Journal of Politics 78: 621-641.

Acharya, Avidit, Matthew Blackwell, and Maya Sen. 2016b. "Explaining causal findings without bias: Detecting and assessing direct effects." American Political Science Review 110: 512-529.

ALLBUS. 2017. "ALLBUS 2016 - Variable Report.” GESIS-Variable Reports Nr. 2017/10. DOI: $10.4232 / 1.12796$

Aronow, Peter M., Jonathon Baron, and Lauren Pinson. 2019. "A note on dropping experimental subjects who fail a manipulation check." Political Analysis 27: 572-589.

Blaydes, Lisa. 2006. "'Rewarding Impatience' Revisited: A Response to Goodrich." International Organization 60: 515-525.

Bruckmeier, Kerstin, Georg-Benedikt Fischer, and Berthold U. Wigger. 2013. "Does Distance Matter? Tuition Fees and Enrollment of First-Year Students at German Public Universities." May 31. CESifo Working Paper Series No. 4258. Available at SSRN. URL: https://ssrn. com/abstract $=2277418$

Charnysh, Volha, and Evgeny Finkel. 2017. "The Death Camp Eldorado: Political and Economic Effects of Mass Violence." American Political Science Review 111: 801818.

Charron, Nicholas, Carl Dahlström, Mihaly Fazekas, and Victor Lapuente. 2017. "Careers, Connections, and Corruption Risks: Investigating the impact of bureaucratic meritocracy on public procurement processes." The Journal of Politics 79: 89-104.

Clark, Tom S., and Drew A. Linzer. 2015. "Should I use fixed or random effects?" Political Science Research and Methods 3: 399-408.

Coppock, Alexander. 2019. "Avoiding post-treatment bias in audit experiments." Journal of Experimental Political Science 6: 1-4.

Dancygier, Rafaela, and Elizabeth N. Saunders. 2006 "A new electorate? Comparing pref- 
erences and partisanship between immigrants and natives." American Journal of Political Science 50: 962-981.

Elwert, Felix, and Christopher Winship. 2014. "Endogenous selection bias: The problem of conditioning on a collider variable." Annual Review of Sociology 40: 31-53.

EVS. 2010. "EVS 2008 Method Report." GESIS-Technical Reports 2010/17. Available at: http://www . europeanvaluesstudy.eu/.

Fouka, Vasiliki, and Hans-Joachim Voth. 2020. "Collective Remembrance and Private Choice: German-Greek Conflict and Consumer Behavior in Times of Crisis." URL: https://vfouka.people.stanford.edu/sites/g/files/sbiybj4871/f/collective_ memory_greece_0.pdf

Gelman, Andrew, and Jennifer Hill. 2006. Data Analysis Using Regression and Multilevel/Hierarchical Models. Cambridge: Cambridge University Press.

Gerber, Alan S., and Donald P. Green. 2012. Field Experiments: Design, Analysis, and Interpretation. New York: W.W. Norton \& Company.

Hawkins, Douglas M. 2004. "The Problem of Overfitting." Journal of Chemical Information and Computer Sciences 44: 1-12.

Hoerner, Julian M., Alexander Jaax, and Toni Rodon. 2019. "The Long-Term Impact of the Location of Concentration Camps on Radical-Right Voting in Germany." Research E Politics. DOI: $10.1177 / 2053168019891376$

Homola, Jonathan, Miguel M. Pereira, and Margit Tavits. 2020. "Legacies of the Third Reich: Concentration Camps and Out-Group Intolerance." American Political Science Review 114: 573-590.

Kelly, Morgan. 2019. "The Standard Errors of Persistence." June 3. Available at SSRN. DOI: $10.2139 /$ ssrn. 3398303

Lax, Jeffrey R., and Justin H. Phillips. 2009. "How should we estimate public opinion in the states?" American Journal of Political Science 53: 107-121.

Levendusky, Matthew S., Jeremy C. Pope, and Simon D. Jackman. 2008. "Measuring 
district-level partisanship with implications for the analysis of US elections." The Journal of Politics 70: 736-753.

Lupu, Noam, and Leonid Peisakhin. 2017. "The legacy of political violence across generations." American Journal of Political Science 61: 836-851.

Maxwell, Rahsaan. 2019. "Cosmopolitan immigration attitudes in large European cities: Contextual or compositional effects?" American Political Science Review 113: 456474.

Mazumder, Soumyajit. 2018. "The Persistent Effect of U.S. Civil Rights Protests on Political Attitudes." American Journal of Political Science 62: 922-935.

Middleton, Joel A., Marc A. Scott, Ronli Diakow, and Jennifer L. Hill. 2016. "Bias amplification and bias unmasking." Political Analysis 24: 307-323.

Mitts, Tamar. 2019. "From isolation to radicalization: anti-Muslim hostility and support for ISIS in the West." American Political Science Review 113: 173-194.

Montgomery, Jacob M., Brendan Nyhan, and Michelle Torres. 2018. "How controlling for post-treatment variables can ruin your experiment and what to do about it." American Journal of Political Science 62: 760-775.

MPIDR [Max Planck Institute for Demographic Research] and CGG [Chair for Geodesy and Geoinformatics, University of Rostock]. 2011. MPIDR Population History GIS Collection (partly based on Hubatsch and Klein 1975 ff). Rostock.

Nunn, Nathan, and Leonard Wantchekon. 2011. "The slave trade and the origins of mistrust in Africa." American Economic Review 101: 3221-3252.

Park, David K., Andrew Gelman, and Joseph Bafumi. 2004. "Bayesian multilevel estimation with poststratification: State-level estimates from national polls." Political Analysis 12: $375-385$.

Pepinsky, Thomas B., Sara Wallace Goodman, and Conrad Ziller. 2020. "Does Proximity to Nazi Concentration Camps Make Germans Intolerant? Modeling Spatial Heterogeneity and Historical Persistence." March 2. Available at SSRN. URL: 
https://papers.ssrn.com/sol3/papers.cfm?abstract_id=3547321

Plümper, Thomas, and Vera E. Troeger. 2019. "Not so Harmless After All: The FixedEffects Model." Political Analysis 27: 21-45.

Rathenow, Hanns-Fred, and Norbert H. Weber. 1995. "Gedenkstättenbesuche im historischpolitischen Unterricht." In Praxis der Gedenkstättenpädagogik, eds. A. Ehmann, W. Kaiser, T. Lutz, H-F. Rathenow, C. vom Stein, N. H. Weber. Opladen: VS Verlag für Sozialwissenschaften: 12-36.

Robins, James M., Donald Blevins, Grant Ritter, and Michael Wulfsohn. 1992. "Gestimation of the effect of prophylaxis therapy for Pneumocystis carinii pneumonia on the survival of AIDS patients." Epidemiology 3: 319-336.

Rosenbaum, Paul R. 1984. "The consequences of adjustment for a concomitant variable that has been affected by the treatment." Journal of the Royal Statistical Society: Series A (General) 147: 656-666.

Rozenas, Arturas, and Yuri M. Zhukov. 2019. "Mass repression and political loyalty: evidence from Stalin's 'Terror by Hunger'." American Political Science Review 113: 569-583.

Rozenas, Arturas, Sebastian Schutte, and Yuri Zhukov. 2017. "The political legacy of violence: The long-term impact of Stalin's repression in Ukraine." The Journal of Politics 79: 1147-1161.

Rueda, David, and Daniel Stegmueller. 2016. "The externalities of inequality: Fear of crime and preferences for redistribution in Western Europe." American Journal of Political Science 60: 472-489.

Sackmann, Rosemarie, and Hartmut Häußermann. 1994. "Do regions matter? Regional differences in female labour-market participation in Germany." Environment and Planning A 26: 1377-1396.

Schündeln, Matthias. 2014. "Are Immigrants More Mobile than Natives? Evidence from Germany." Journal of Regional Science 54: 70-95. 
Selb, Peter, and Simon Munzert. 2011. "Estimating constituency preferences from sparse survey data using auxiliary geographic information." Political Analysis 19: 455-470. Simpser, Alberto, Dan Slater, and Jason Wittenberg. 2018. "Dead But Not Gone: Contemporary Legacies of Communism, Imperialism, and Authoritarianism." Annual Review of Political Science 21: 419-439.

Vansteelandt, Sijn. 2009. "Estimating Direct Effects in Cohort and Case-Control Studies." Epidemiology 20: 851-860.

Weber, Reinhold, and Iris Häuser. 2008. Baden-Württemberg: Eine kleine politische Landeskunde. Stuttgart: Landeszentrale für politische Bildung Baden-Württemberg.

Voigtländer, Nico, and Hans-Joachim Voth. 2012. "Persecution perpetuated: the medieval origins of anti-Semitic violence in Nazi Germany." The Quarterly Journal of Economics 127: 1339-1392.

Ziblatt, Daniel, Hanno Hilbig, and Daniel Bischof. 2020. "Parochialism and the radicalright: Place-based social identity and voting behavior in Germany." Available at: https://osf.io/preprints/socarxiv/syr84/. 


\section{Supplementary Information "Fixed Effects and a Legacy of Post-Treatment Bias"}

This supplementary information file includes the following sections:

- SI1 (p. 1-2): Comparison of model specifications

- SI2 (p. 3-5): Additional post-treatment bias discussion

- SI3 (p. 6-10): Additional analyses using electoral data

- SI4 (p. 11-19): Additional analyses using EVS data

- SI5 (p. 20-22): Additional analyses using one mediating variable

- SI6 (p. 23-27): Prussian provinces: discussion and additional analyses

- SI7 (p. 28-32): Noise simulations

- SI8 (p. 33-35): Inconsistencies in PGZ

- SI9 (p. 36): Inappropriateness of Moran statistic for survey data

- SI10 (p. 37-38): References used in the SI 


\section{SI1: Comparison of model specifications}

Together, HPT, PGZ, and the current note provide an extensive list of models with different data sources and model specifications. To help the reader follow this collective effort, Table SI1.1 summarizes the different main specifications modeling the effect of camp proximity on contemporary outcomes.

More specifically, we report the results of the main specifications in HPT in Columns 1 (OLS) and 2 (g-estimator). The main results in PGZ are reported in Columns 3 (contemporary state fixed effects) and 4 (Weimar-era state fixed effects). Finally, the main results of the new model specifications in the current paper are presented across Columns 5 (contemporary state fixed effects only in the first stage of the g-estimator), 6 (Weimar-era state fixed effects in both stages), and 7 (contemporary state fixed effects only in the first stage and Weimar-era state fixed effects in both stages). The models with hybrid fixed effects (Weimar states and Prussian provinces) are discussed in SI 6.

Estimates highlighted in green are in line with the theoretical expectations in HPT and reliable at conventional levels. Estimates highlighted in yellow are in line with the theoretical expectations in HPT but not reliable at conventional levels. Across all the different specifications, the only results that go against the original expectations in HPT can be found

in Column 3, which present PGZ's models that suffer from post-treatment bias as explained in the main text. In contrast, PGZ's models that appropriately use Weimar-era fixed effects provide estimates that are in line with HPT. 


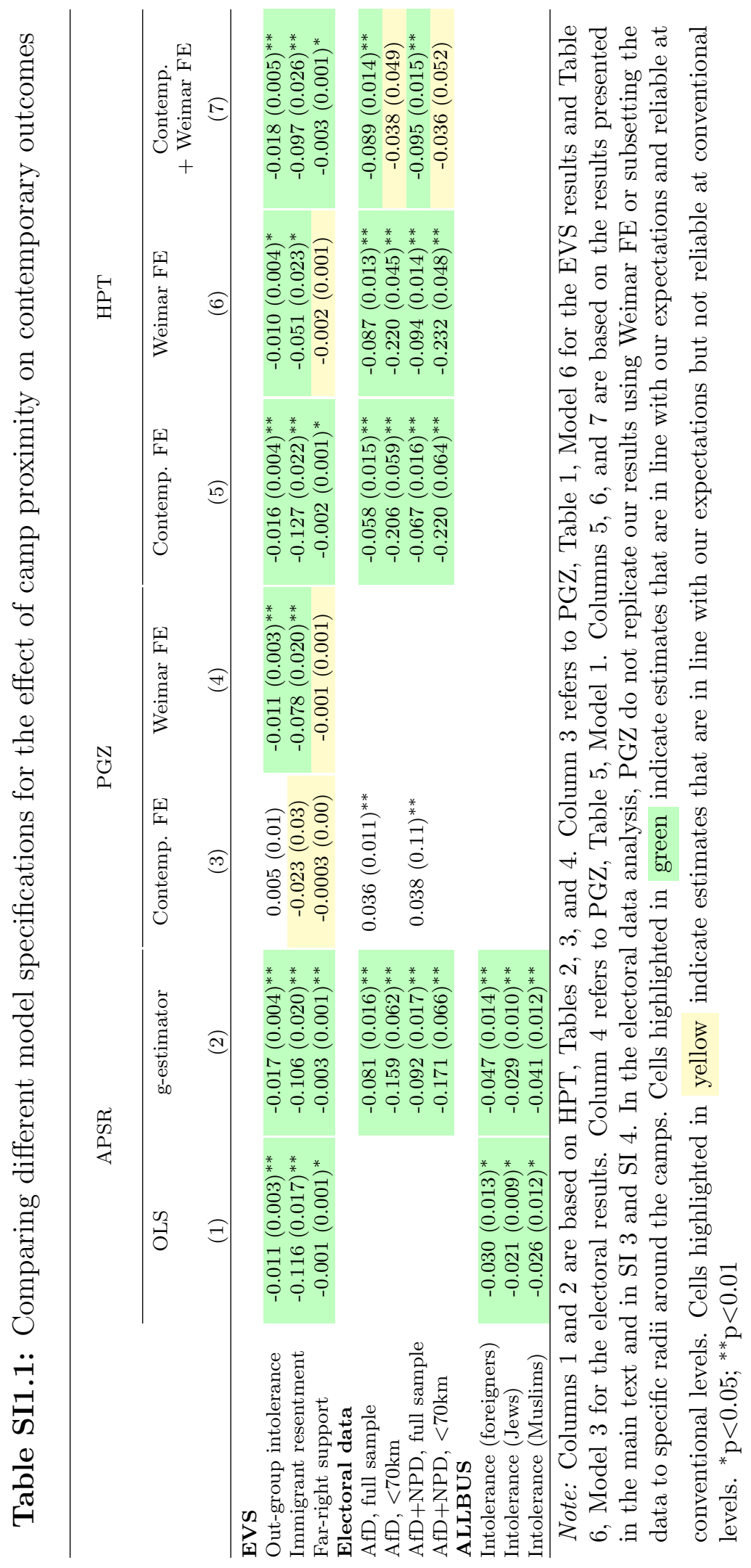




\section{SI2: Additional post-treatment bias discussion}

In the main text, we use qualitative knowledge of the case to show that the inclusion of state fixed effects is likely to induce post-treatment bias. Here, we make the same point formally using PGZ's notation and assumptions, while also showing that their definition of potential post-treatment bias is incomplete.

More specifically, PGZ discuss that there are three conditions that must be fulfilled to consider state fixed effects a (bias-inducing) collider (p. 7):

$$
\begin{gathered}
S \leftarrow U_{S, Y} \rightarrow Y \\
D \leftarrow U_{D, S} \rightarrow S \\
U_{S, Y} \nrightarrow \succ D
\end{gathered}
$$

Where $S$ represents state-level differences, $Y$ is the outcome variable, $D$ represents camp proximity, and $U_{x, y}$ represents any unobserved variable explaining both $x$ and $y$. PGZ claim that "this is a knife-edge result and we are aware of no theoretical argument that would decompose the unobserved joint determinants of values, state boundaries, and camp locations in this way" (p. 7). However, we argue that (i) we do not find the conditions implausible and do not think that this is "a knife-edge result" at all, and (ii) the fulfillment of all of those conditions is not necessary to categorize state fixed effects as a collider.

1. Plausibility of post-treatment bias conditions: We do not find the conditions PGZ present implausible. Starting with their third condition $\left(U_{S, Y} \nrightarrow D\right)$, this condition seems extremely reasonable once we take into account the temporal structure of the variables: $U_{S, Y}$ represents unmeasured confounders of variables (the states $S$ and our outcome $Y$ ) that were realized and measured after our treatment. Therefore, it seems implausible that these confounders would act as determinants of the treatment itself. As we discuss in the main text, arguing against this condition would mean trying to predict the past with the present. Moreover, the fulfillment of this condition is in fact implied in the sequential ignorability assumption 
of the g-estimation approach.

Turning to conditions one and two, the existence of unmeasured confounders $U_{D, S}$ and $U_{S, Y}$ is as plausible as in any other study in political science dealing with correlated variables. For example, we can think of the Weimar-era states as unmeasured confounders $U_{D, S}$ in the sense that they are associated with the distance to camps and also played an important role in the generation of the post-war states. Finally, $U_{S, Y}$ are unmeasured confounders affecting both state-level differences and the outcome variable. Any heterogeneous economic shock (e.g., a spike in local unemployment in a single municipality) can affect both individual attitudes towards out-groups as well as variation at the state level (e.g., in policies), which the state-level fixed effects are picking up.

2. State fixed effects as a post-treatment inducing collider: In order to see why and when state fixed effects are inducing post-treatment bias, we will not focus our notation on the unmeasured confounders like PGZ, but instead on the fixed effects $(S)$ themselves. This allows us to show that not all three of PGZ's conditions have to be true for post-treatment bias to exist. Instead, only one of the following two conditions has to be true:

$$
\begin{aligned}
D & \rightarrow S \leftarrow U_{S, Y} \rightarrow Y \\
\text { or, } \quad D \leftarrow U_{D, S} & \rightarrow S \leftarrow U_{S, Y} \rightarrow Y
\end{aligned}
$$

In other words, there are two paths connecting distance to camps $(D)$ and our outcome variables $(Y)$ on which we can identify state fixed effects $(S)$ as a post-treatment collider. More specifically, as long as there is either a) an effect of distance on borders/states $(D \rightarrow S)$ and a common cause of the latter and values $\left(S \leftarrow U_{S, Y} \rightarrow Y\right)$, or b) unmeasured confounders of distance and states $\left(D \leftarrow U_{D, S} \rightarrow S\right)$, as well as states and values $\left(S \leftarrow U_{S, Y} \rightarrow Y\right)$, then $S$ becomes a collider inducing bias if we condition on it in a normal regression setting. As we explain in the main text and above, it is very likely that at least one if not both 
of these conditions is fulfilled. Fortunately, the g-estimation approach allows us to include intermediate confounders that act as colliders, such as $S$, as long as we include them in the first stage of the model used to estimate the effect of the mediator on the outcome. As we show in the main text, our results are robust to this approach. 


\section{SI3: Additional analyses using electoral data}

This section presents the full results for the main analysis of the electoral data presented in the manuscript, as well as some additional analyses. More specifically, Tables SI3.1-SI3.3 display the full regression results for the analysis presented in Figure 3. In the main text, we describe that matching contemporary geographical units with Weimar-era states is not straightforward. Whereas our main results rely on the approach we describe as centroid interpolation in the main text, Figure SI3.1 shows that the findings are also robust to using the other matching approaches described (i.e., centroid interpolation while also including Saarland respondents, and area interpolation). 
Table SI3.1: The controlled direct effect of camp proximity on support for radical right parties in 2017, with current state fixed effects in first stage of g-estimator

\begin{tabular}{lcccc}
\hline & \multicolumn{2}{c}{ AfD Vote Share } & AfD + NPD Vote Share \\
\cline { 2 - 5 } & Full sample & $<70 k m$ & Full sample & $<70 k m$ \\
& $(1)$ & $(2)$ & $(3)$ & $(4)$ \\
\hline Distance & $-0.058^{* *}$ & $-0.206^{* *}$ & $-0.067^{* *}$ & $-0.220^{* *}$ \\
in 10kms) & $(0.015)$ & $(0.059)$ & $(0.016)$ & $(0.064)$ \\
Nazi party share (1933) & 0.008 & -0.004 & $0.012^{*}$ & 0.0004 \\
& $(0.005)$ & $(0.010)$ & $(0.006)$ & $(0.010)$ \\
\% Unemployed (1933) & $0.168^{* *}$ & $0.120^{* *}$ & $0.177^{* *}$ & $0.129^{* *}$ \\
& $(0.028)$ & $(0.033)$ & $(0.030)$ & $(0.036)$ \\
Population (1925) & 0.00000 & 0.00000 & 0.00000 & 0.00000 \\
\% Jews (1925) & $(0.00000)$ & $(0.00001)$ & $(0.00000)$ & $(0.00001)$ \\
& $-2.969^{* *}$ & $-4.306^{* *}$ & $-3.144^{* *}$ & $-4.604^{* *}$ \\
\hline Current state FEs (N=16) & $(0.147)$ & $(0.458)$ & $(0.155)$ & $(0.484)$ \\
Contemporary variables & $\checkmark$ & $\checkmark$ & $\checkmark$ & $\checkmark$ \\
\hline Observations & $\checkmark$ & $\checkmark$ & $\checkmark$ & $\checkmark$ \\
Adjusted R & 10,755 & 3,949 & 10,755 & 3,949 \\
\hline
\end{tabular}

Note: Entries are coefficients of the controlled direct effect of distance to closest camp on support for the AfD (Columns 1-2) and AfD+NPD (Column 3-4) in 2017, corresponding to Table 4 in Homola et al. (2020). All models report the second stage of the sequential gestimator (bootstrapped standard errors in parentheses). All models include contemporary state fixed effects and contemporary mediators and confounders in the first stage regression. ${ }^{*} \mathrm{p}<0.05 ;{ }^{* *} \mathrm{p}<0.01$ 
Table SI3.2: The controlled direct effect of camp proximity on support for radical right parties in 2017, accounting for systematic differences across Weimar states (interpolated from centroids of contemporary Gemeinden)

\begin{tabular}{|c|c|c|c|c|}
\hline & \multicolumn{2}{|c|}{ AfD Vote Share } & \multicolumn{2}{|c|}{ AfD + NPD Vote Share } \\
\hline & $\begin{array}{l}\text { Full sample } \\
\qquad(1)\end{array}$ & $\begin{array}{c}<70 k m \\
(2)\end{array}$ & $\begin{array}{l}\text { Full sample } \\
\qquad(3)\end{array}$ & $\begin{array}{c}<70 k m \\
(4)\end{array}$ \\
\hline $\begin{array}{l}\text { Distance } \\
\text { (in } 10 \mathrm{kms})\end{array}$ & $\begin{array}{c}-0.087^{* *} \\
(0.013)\end{array}$ & $\begin{array}{c}-0.220^{* *} \\
(0.045)\end{array}$ & $\begin{array}{c}-0.094^{* *} \\
(0.014)\end{array}$ & $\begin{array}{c}-0.232^{* *} \\
(0.048)\end{array}$ \\
\hline Nazi party share (1933) & $\begin{array}{c}-0.028^{* *} \\
(0.004)\end{array}$ & $\begin{array}{c}-0.039^{* *} \\
(0.008)\end{array}$ & $\begin{array}{c}-0.028^{* *} \\
(0.004)\end{array}$ & $\begin{array}{c}-0.040^{* *} \\
(0.008)\end{array}$ \\
\hline \% Unemployed (1933) & $\begin{array}{l}0.055^{* *} \\
(0.015)\end{array}$ & $\begin{array}{c}0.027 \\
(0.019)\end{array}$ & $\begin{array}{l}0.054^{* *} \\
(0.016)\end{array}$ & $\begin{array}{c}0.028 \\
(0.021)\end{array}$ \\
\hline Population (1925) & $\begin{array}{l}-0.00000 \\
(0.00000)\end{array}$ & $\begin{array}{c}0.00001 \\
(0.00001)\end{array}$ & $\begin{array}{l}-0.00000 \\
(0.00000)\end{array}$ & $\begin{array}{c}0.00001 \\
(0.00001)\end{array}$ \\
\hline \% Jews (1925) & $\begin{array}{c}-0.505^{* *} \\
(0.117) \\
\end{array}$ & $\begin{array}{c}-1.001^{* *} \\
(0.260)\end{array}$ & $\begin{array}{c}-0.519^{* *} \\
(0.122) \\
\end{array}$ & $\begin{array}{c}-1.105^{* *} \\
(0.272)\end{array}$ \\
\hline Weimar state FEs $(\mathrm{N}=17)$ & $\checkmark$ & $\checkmark$ & $\checkmark$ & $\checkmark$ \\
\hline Contemporary variables & $\checkmark$ & $\checkmark$ & $\checkmark$ & $\checkmark$ \\
\hline Observations & 10,737 & 3,945 & 10,737 & 3,945 \\
\hline Adjusted $\mathrm{R}^{2}$ & 0.390 & 0.361 & 0.389 & 0.364 \\
\hline
\end{tabular}

Note: Entries are coefficients of the controlled direct effect of distance to closest camp on support for the AfD (Columns 1-2) and AfD+NPD (Column 3-4) in 2017, corresponding to Table 4 in Homola et al. (2020). All models report the second stage of the sequential gestimator (bootstrapped standard errors in parentheses). All models include Weimar state fixed effects (interpolated based on the centroids of contemporary Gemeinden) in both stages and contemporary mediators and confounders in the first stage regression. ${ }^{*} \mathrm{p}<0.05 ;{ }^{* *} \mathrm{p}<0.01$ 
Table SI3.3: The controlled direct effect of camp proximity on support for radical right parties in 2017, with current state fixed effects in first stage of g-estimator and accounting for systematic differences across Weimar states (interpolated from centroids of contemporary Gemeinden)

\begin{tabular}{lcccc}
\hline & \multicolumn{2}{c}{ AfD Vote Share } & \multicolumn{2}{c}{ AfD + NPD Vote Share } \\
\cline { 2 - 5 } & Full sample & $<70 k m$ & Full sample & $<70 k m$ \\
& $(1)$ & $(2)$ & $(3)$ & $(4)$ \\
\hline Distance & $-0.089^{* *}$ & -0.038 & $-0.095^{* *}$ & -0.036 \\
(in 10kms) & $(0.014)$ & $(0.049)$ & $(0.015)$ & $(0.052)$ \\
Nazi party share (1933) & $0.009^{*}$ & 0.006 & $0.012^{* *}$ & 0.009 \\
& $(0.004)$ & $(0.009)$ & $(0.005)$ & $(0.010)$ \\
\% Unemployed (1933) & $0.080^{* *}$ & $0.085^{*}$ & $0.081^{* *}$ & $0.091^{*}$ \\
& $(0.018)$ & $(0.033)$ & $(0.019)$ & $(0.036)$ \\
Population (1925) & -0.00000 & 0.00000 & $-0.00000^{*}$ & 0.00000 \\
& $(0.00000)$ & $(0.00001)$ & $(0.00000)$ & $(0.00001)$ \\
\% Jews (1925) & $-1.088^{* *}$ & $-1.914^{* *}$ & $-1.150^{* *}$ & $-2.089^{* *}$ \\
& $(0.127)$ & $(0.354)$ & $(0.132)$ & $(0.374)$ \\
\hline Current state FEs (N=16) & $\checkmark$ & $\checkmark$ & $\checkmark$ & $\checkmark$ \\
Weimar state FEs (N=17) & $\checkmark$ & $\checkmark$ & $\checkmark$ & $\checkmark$ \\
Contemporary variables & $\checkmark$ & $\checkmark$ & $\checkmark$ & $\checkmark$ \\
\hline Observations & 10,737 & 3,945 & 10,737 & 3,945 \\
Adjusted R ${ }^{2}$ & 0.415 & 0.410 & 0.416 & 0.417 \\
\hline
\end{tabular}

Note: Entries are coefficients of the controlled direct effect of distance to closest camp on support for the AfD (Columns 1-2) and AfD+NPD (Column 3-4) in 2017, corresponding to Table 4 in Homola et al. (2020). All models report the second stage of the sequential gestimator (bootstrapped standard errors in parentheses). All models include contemporary state fixed effects and contemporary mediators and confounders in the first stage regression. All models also include Weimar state fixed effects (interpolated based on the centroids of contemporary Gemeinden) in both stages. ${ }^{*} \mathrm{p}<0.05 ;{ }^{* *} \mathrm{p}<0.01$ 
Figure SI3.1: The controlled direct effect of camp proximity on support for radical right parties in 2017, with alternative methods to interpolate Weimar states from contemporary Gemeinden

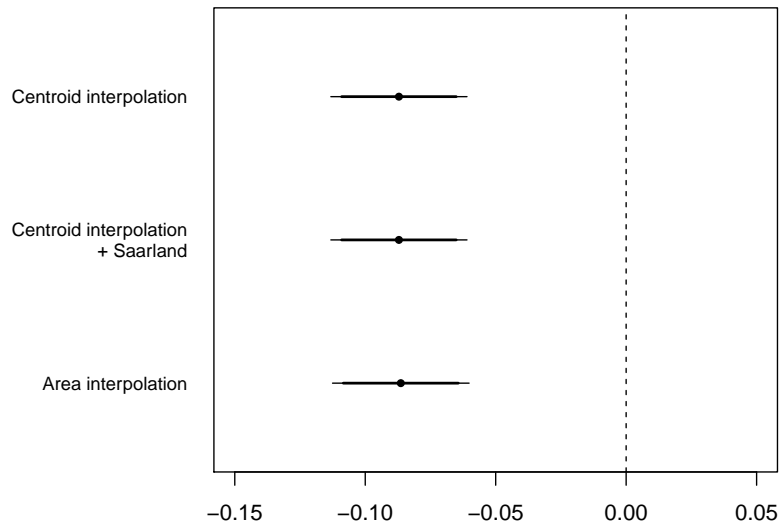

(a) AfD, full sample

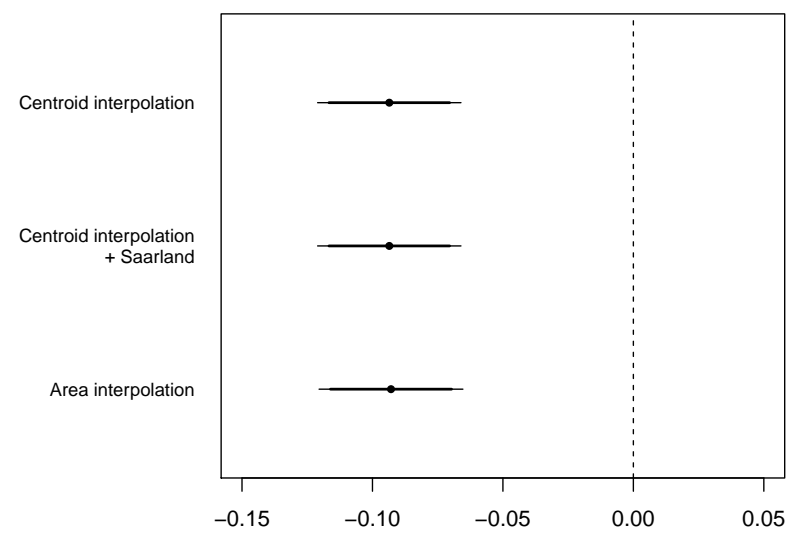

(c) AfD+NPD, full sample

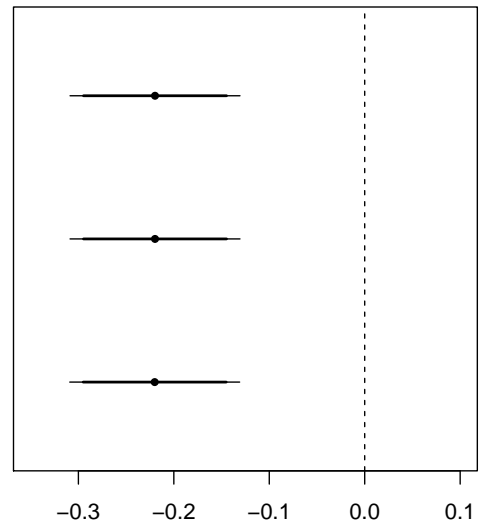

(b) AfD, $70 \mathrm{~km}$ radius

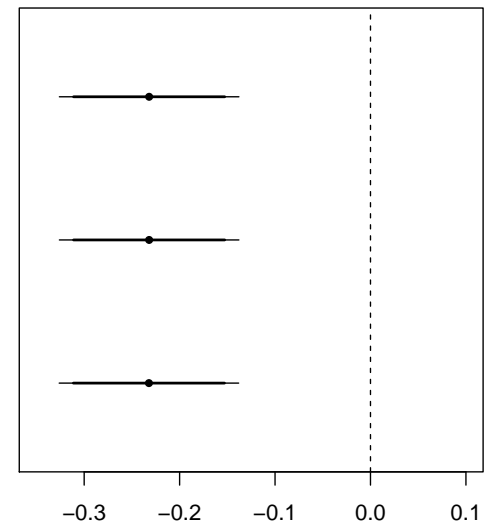

(d) $\mathrm{AfD}+\mathrm{NPD}, 70 \mathrm{~km}$ radius

Note: Plots depict estimates and 95/90\% confidence intervals from the sequential g-estimator for the controlled direct effects of distance to camps on support for radical right parties in 2017 (described in each panel label). Each estimate corresponds to a different model based on alternative methods to match contemporary districts with Weimar-era states. 


\section{SI4: Additional analyses using EVS data}

This section presents descriptive statistics and supplementary analyses of the EVS data. Tables SI4.1-SI4.3 describe the number of EVS observations and primary sampling units (PSUs) by state, and by state and Prussian province. Each primary sampling unit corresponds to a unique measure of camp proximity. Hence, PSUs capture the range of distances available in each subregion. As an example, in the OLS models with Weimar states and provinces (Table SI4.3) ten out of 24 regions have either one or two unique values of the key predictor.

Tables SI4.4-SI4.6, in turn, display the full regression results for the analysis presented in Figure 4. In the main text, we describe that matching contemporary geographical units with Weimar-era states is not straightforward. Whereas our main results rely on the approach we describe as centroid interpolation in the main text, Figure SI4.1 shows that the findings are also robust to using the other matching approaches described (i.e., centroid interpolation while also including Saarland respondents and area interpolation). Finally, while these main models are all replications of our g-estimation approach, the results in Figure SI4.2 show that the "pre-treatment only" OLS models are also robust to the properly specified inclusion of state fixed effects. 
Table SI4.1: Number of EVS observations and primary sampling units by current-day state

\begin{tabular}{lcc}
\hline & \multicolumn{2}{c}{ Model Specification } \\
\cline { 2 - 3 } Contemporary State & OLS & G-Estimator \\
\hline Baden-Württemberg & $180(13)$ & $130(13)$ \\
Bavaria & $186(15)$ & $140(15)$ \\
Berlin & $58(1)$ & $34(1)$ \\
Brandenburg & $205(11)$ & $149(11)$ \\
Bremen & $17(2)$ & $8(2)$ \\
Hamburg & $30(1)$ & $21(1)$ \\
Hessen & $92(10)$ & $34(9)$ \\
Lower Saxony & $135(12)$ & $98(12)$ \\
Mecklenburg-Vorpommern & $102(8)$ & $52(8)$ \\
North Rhine-Westphalia & $301(23)$ & $219(23)$ \\
Rhineland Palatinate & $37(4)$ & $18(4)$ \\
Saarland & $20(3)$ & $1(1)$ \\
Saxony & $314(12)$ & $180(12)$ \\
Saxony-Anhalt & $212(14)$ & $162(14)$ \\
Schleswig-Holstein & $51(6)$ & $39(6)$ \\
Thuringia & $135(15)$ & $91(15)$ \\
\hline Total & $2075(150)$ & $1376(147)$ \\
\hline
\end{tabular}

Note: Entries are the number of EVS observations and the number of unique values of camp proximity (in parenthesis) by current-day state in Germany, according to the model specification described in the column header. 
Table SI4.2: Number of EVS observations and primary sampling units by Weimar state

\begin{tabular}{lcc}
\hline & \multicolumn{2}{c}{ Model Specification } \\
\cline { 2 - 3 } Weimar State & OLS & G-Estimator \\
\hline Anhalt & $22(3)$ & $17(3)$ \\
Baden & $63(5)$ & $41(5)$ \\
Bavaria & $195(16)$ & $141(16)$ \\
Bremen & $15(1)$ & $6(1)$ \\
Brunswick & $12(1)$ & $1(1)$ \\
Hamburg & $30(1)$ & $21(1)$ \\
Hesse & $15(2)$ & $5(1)$ \\
Mecklenburg-Schwerin & $93(6)$ & $39(6)$ \\
Mecklenburg-Strelitz & $12(1)$ & $9(1)$ \\
Oldenburg & $12(1)$ & $5(1)$ \\
Prussia & $1072(78)$ & $770(78)$ \\
Saxony & $267(10)$ & $150(10)$ \\
Schaumburg-Lippe & $11(1)$ & $3(1)$ \\
Thuringia & $111(12)$ & $74(12)$ \\
Württenberg & $125(9)$ & $93(9)$ \\
\hline Total & $2055(147)$ & $1375(146)$ \\
\hline
\end{tabular}

Note: Entries are the number of EVS observations and the number of unique values of camp proximity (in parenthesis) by Weimar states in Germany, according to the model specification described in the column header. 
Table SI4.3: Number of EVS observations and primary sampling units by Weimar state and Prussian province

\begin{tabular}{|c|c|c|}
\hline \multirow[b]{2}{*}{ State/Province } & \multicolumn{2}{|c|}{ Model Specification } \\
\hline & OLS & G-Estimator \\
\hline \multicolumn{3}{|l|}{ Weimar State } \\
\hline Anhalt & $22(3)$ & $17(3)$ \\
\hline Baden & $63(5)$ & $41(5)$ \\
\hline Bavaria & $195(16)$ & $141(16)$ \\
\hline Bremen & $15(1)$ & $6(1)$ \\
\hline Brunswick & $12(1)$ & $1(1)$ \\
\hline Hamburg & $30(1)$ & $21(1)$ \\
\hline Hesse & $15(2)$ & $5(1)$ \\
\hline Mecklenburg-Schwerin & $93(6)$ & $39(6)$ \\
\hline Mecklenburg-Strelitz & $12(1)$ & $9(1)$ \\
\hline Oldenburg & $12(1)$ & $5(1)$ \\
\hline Saxony & $267(10)$ & $150(10)$ \\
\hline Schaumburg-Lippe & $11(1)$ & $3(1)$ \\
\hline Thuringia & $111(12)$ & $74(12)$ \\
\hline Wurttenberg & $125(9)$ & $93(9)$ \\
\hline \multicolumn{3}{|l|}{ Prussian Province } \\
\hline Berlin & $58(1)$ & $34(1)$ \\
\hline Brandenburg & $182(10)$ & $137(10)$ \\
\hline Hanover & $114(11)$ & $92(11)$ \\
\hline Hesse-Nassau & $69(7)$ & $25(7)$ \\
\hline Lower Silesia & $27(1)$ & $16(1)$ \\
\hline Pomerania & $20(2)$ & $16(2)$ \\
\hline Rhineland & $137(13)$ & $102(13)$ \\
\hline Saxony & $222(14)$ & $175(14)$ \\
\hline Schleswig & $51(6)$ & $39(6)$ \\
\hline Westphalia & $192(13)$ & $134(13)$ \\
\hline Total & $2055(147)$ & $1375(146)$ \\
\hline
\end{tabular}

Note: Entries are the number of EVS observations and the number of unique values of camp proximity (in parenthesis) by Weimar states and Prussian provinces in Germany, according to the model specification described in the column header. 
Table SI4.4: The controlled direct effect of camp proximity on contemporary attitudes, with current state fixed effects in first stage of g-estimator

\begin{tabular}{|c|c|c|c|c|c|c|}
\hline & \multicolumn{2}{|c|}{$\begin{array}{l}\text { Outgroup } \\
\text { Intolerance }\end{array}$} & \multicolumn{2}{|c|}{$\begin{array}{l}\text { Immigrant } \\
\text { Resentment }\end{array}$} & \multicolumn{2}{|c|}{$\begin{array}{c}\text { Support } \\
\text { Far-Right Parties }\end{array}$} \\
\hline & $(1)$ & $(2)$ & $(3)$ & $(4)$ & $(5)$ & $(6)$ \\
\hline $\begin{array}{l}\text { Distance to camp } \\
\text { (in } 10 \mathrm{kms} \text { ) }\end{array}$ & $\begin{array}{c}0.005 \\
(0.005)\end{array}$ & $\begin{array}{c}-0.016^{* *} \\
(0.004)\end{array}$ & $\begin{array}{l}-0.023 \\
(0.029)\end{array}$ & $\begin{array}{c}-0.127^{* *} \\
(0.022)\end{array}$ & $\begin{array}{c}-0.0003 \\
(0.001)\end{array}$ & $\begin{array}{r}-0.002^{*} \\
(0.001)\end{array}$ \\
\hline \% Jews (1925) & $\begin{array}{l}7.561 \\
(6.289)\end{array}$ & $\begin{array}{l}-0.782 \\
(1.609)\end{array}$ & $\begin{array}{l}-5.063 \\
(35.980)\end{array}$ & $\begin{array}{c}0.185 \\
(11.344)\end{array}$ & $\begin{array}{c}1.891 \\
(1.564)\end{array}$ & $\begin{array}{c}0.336 \\
(0.454)\end{array}$ \\
\hline \% Unemployed (1933) & $\begin{array}{l}1.321 \\
(0.909)\end{array}$ & $\begin{array}{l}2.177^{*} \\
(0.934)\end{array}$ & $\begin{array}{l}1.837 \\
(5.202)\end{array}$ & $\begin{array}{l}12.369^{*} \\
(5.694)\end{array}$ & $\begin{array}{c}0.266 \\
(0.226)\end{array}$ & $\begin{array}{c}0.299 \\
(0.195)\end{array}$ \\
\hline Population (1925) & $\begin{array}{l}-0.017 \\
(0.016)\end{array}$ & $\begin{array}{l}-0.013 \\
(0.012)\end{array}$ & $\begin{array}{l}-0.108 \\
(0.093)\end{array}$ & $\begin{array}{l}-0.104 \\
(0.077)\end{array}$ & $\begin{array}{l}-0.006 \\
(0.004)\end{array}$ & $\begin{array}{c}-0.0004 \\
(0.003)\end{array}$ \\
\hline Nazi party share (1933) & $\begin{array}{c}-0.726^{* *} \\
(0.280) \\
\end{array}$ & $\begin{array}{l}-0.244 \\
(0.242) \\
\end{array}$ & $\begin{array}{c}-5.109^{* *} \\
(1.605) \\
\end{array}$ & $\begin{array}{c}-3.705^{*} \\
(1.696) \\
\end{array}$ & $\begin{array}{c}-0.170^{*} \\
(0.070) \\
\end{array}$ & $\begin{array}{l}-0.078 \\
(0.063)\end{array}$ \\
\hline $\begin{array}{l}\text { Model } \\
\text { Current state FEs }(\mathrm{N}=16) \\
\text { Contemporary covariates }\end{array}$ & $\begin{array}{l}\text { G-est. } \\
\text { Stage } 1 \\
\checkmark \\
\checkmark \\
\end{array}$ & $\begin{array}{l}\text { G-est. } \\
\text { Stage } 2\end{array}$ & $\begin{array}{l}\text { G-est. } \\
\text { Stage } 1 \\
\checkmark \\
\checkmark \\
\end{array}$ & $\begin{array}{c}\text { G-est. } \\
\text { Stage } 2\end{array}$ & $\begin{array}{l}\text { G-est. } \\
\text { Stage } 1 \\
\checkmark \\
\checkmark\end{array}$ & $\begin{array}{l}\text { G-est. } \\
\text { Stage } 2\end{array}$ \\
\hline Observations & 1,376 & 1,376 & 1,376 & 1,376 & 1,376 & 1,376 \\
\hline Adjusted $\mathrm{R}^{2}$ & 0.117 & 0.025 & 0.215 & 0.042 & 0.240 & 0.016 \\
\hline
\end{tabular}

Note: Entries are coefficients of the effect of distance to closest camp on different outcomes, described in the column headers. Model 1, 3, and 5 correspond to the first stage of the sequential g-estimation (standard errors in parentheses), with contemporary covariates including current state fixed effects. Models 2, 4, and 6, represent the second stage in the sequential g-estimation (bootstrapped standard errors in parentheses). ${ }^{*} \mathrm{p}<0.05 ;{ }^{* *} \mathrm{p}<0.01$ 
Table SI4.5: Effects of camp proximity on out-group intolerance, immigrant resentment, and support for far-right parties (EVS), accounting for systematic differences across Weimar states (interpolated from centroids of contemporary Kreise)

\begin{tabular}{lcccccc}
\hline & \multicolumn{2}{c}{$\begin{array}{c}\text { Out-group } \\
\text { Intolerance }\end{array}$} & \multicolumn{2}{c}{$\begin{array}{c}\text { Immigrant } \\
\text { Resentment }\end{array}$} & \multicolumn{2}{c}{ Far-Right Parties } \\
\cline { 2 - 7 } & $(1)$ & $(2)$ & $(3)$ & $(4)$ & $(5)$ & $(6)$ \\
\hline Distance to camp & $-0.011^{* *}$ & $-0.010^{*}$ & $-0.077^{* *}$ & $-0.051^{*}$ & -0.001 & -0.002 \\
(in 10kms) & $(0.003)$ & $(0.004)$ & $(0.020)$ & $(0.023)$ & $(0.001)$ & $(0.001)$ \\
\% Jews (1925) & -1.876 & -0.580 & 8.532 & 16.023 & -0.077 & 0.183 \\
& $(1.192)$ & $(1.494)$ & $(7.037)$ & $(9.978)$ & $(0.268)$ & $(0.474)$ \\
\% Unemployed (1933) & $2.344^{* *}$ & $3.128^{* *}$ & 0.143 & 11.169 & 0.107 & $0.682^{* *}$ \\
& $(0.719)$ & $(0.915)$ & $(4.243)$ & $(5.799)$ & $(0.162)$ & $(0.237)$ \\
Population (1925) & $-0.037^{* *}$ & 0.005 & $-0.300^{* *}$ & -0.064 & -0.003 & -0.001 \\
& $(0.012)$ & $(0.014)$ & $(0.071)$ & $(0.099)$ & $(0.003)$ & $(0.003)$ \\
Nazi party share (1933) & $-0.466^{*}$ & -0.418 & $-2.796^{*}$ & $-5.806^{* *}$ & -0.021 & -0.082 \\
& $(0.196)$ & $(0.217)$ & $(1.156)$ & $(1.490)$ & $(0.044)$ & $(0.056)$ \\
\hline Model & OLS & G-est. & OLS & G-est. & OLS & G-est. \\
Weimar state FEs (N $=$ & $\checkmark$ & $\checkmark$ & $\checkmark$ & $\checkmark$ & $\checkmark$ & $\checkmark$ \\
Contemporary variables & & $\checkmark$ & & $\checkmark$ & & $\checkmark$ \\
\hline Observations & 2,055 & 1,375 & 2,055 & 1,375 & 2,055 & 1,375 \\
Adjusted R $\mathrm{R}^{2}$ & 0.045 & 0.057 & 0.075 & 0.096 & 0.005 & 0.034 \\
\hline
\end{tabular}

Note: Entries are estimates of the effect of distance to closest camp on the different outcomes, described in column headers. Models 1, 3, and 5 account exclusively for interwar covariates (standard errors in parentheses). Models 2, 4, and 6 are the 2nd stage of the sequential g-estimator to also account for contemporary predictors (bootstrapped standard errors in parentheses). All models (and both stages of the g-estimator) include Weimar state fixed effects (interpolated based on the centroids of contemporary Kreise). ${ }^{*} \mathrm{p}<0.05 ;{ }^{* *} \mathrm{p}<0.01$ 
Table SI4.6: The controlled direct effect of camp proximity on out-group intolerance, immigrant resentment, and support for far-right parties (EVS), with current state fixed effects in first stage of g-estimator and accounting for systematic differences across Weimar states (interpolated from centroids of contemporary Kreise)

\begin{tabular}{|c|c|c|c|}
\hline & $\begin{array}{l}\text { Out-group } \\
\text { Intolerance }\end{array}$ & $\begin{array}{l}\text { Immigrant } \\
\text { Resentment }\end{array}$ & $\begin{array}{c}\text { Support } \\
\text { Far-Right Parties }\end{array}$ \\
\hline & $(1)$ & $(2)$ & $(3)$ \\
\hline $\begin{array}{l}\text { Distance to camp } \\
\text { (in } 10 \mathrm{kms} \text { ) }\end{array}$ & $\begin{array}{c}-0.018^{* *} \\
(0.005)\end{array}$ & $\begin{array}{c}-0.097^{* *} \\
(0.026)\end{array}$ & $\begin{array}{c}-0.003^{*} \\
(0.001)\end{array}$ \\
\hline \% Jews (1925) & $\begin{array}{l}-1.690 \\
(1.521)\end{array}$ & $\begin{array}{c}9.171 \\
(10.410)\end{array}$ & $\begin{array}{c}0.002 \\
(0.466)\end{array}$ \\
\hline \% Unemployed (1933) & $\begin{array}{l}3.142^{* *} \\
(1.037)\end{array}$ & $\begin{array}{c}7.614 \\
(6.063)\end{array}$ & $\begin{array}{l}0.604^{*} \\
(0.238)\end{array}$ \\
\hline Population (1925) & $\begin{array}{l}-0.007 \\
(0.015)\end{array}$ & $\begin{array}{l}-0.173 \\
(0.110)\end{array}$ & $\begin{array}{l}-0.003 \\
(0.004)\end{array}$ \\
\hline Nazi party share (1933) & $\begin{array}{l}-0.249 \\
(0.229)\end{array}$ & $\begin{array}{c}-4.632^{* *} \\
(1.564)\end{array}$ & $\begin{array}{l}-0.055 \\
(0.059)\end{array}$ \\
\hline Model & G-est. & G-est. & G-est. \\
\hline Current state FEs $(\mathrm{N}=16)$ & $\checkmark$ & $\checkmark$ & $\checkmark$ \\
\hline Weimar state FEs $(\mathrm{N}=16)$ & $\checkmark$ & $\checkmark$ & $\checkmark$ \\
\hline Contemporary variables & $\checkmark$ & $\checkmark$ & $\checkmark$ \\
\hline Observations & 1,375 & 1,375 & 1,375 \\
\hline Adjusted $\mathrm{R}^{2}$ & 0.039 & 0.080 & 0.019 \\
\hline
\end{tabular}

Note: Entries are estimates of the controlled direct effect of distance to closest camp on the different outcomes, described in column headers. All models report the second stage of the sequential g-estimator (bootstrapped standard errors in parentheses). All models include contemporary state fixed effects and contemporary mediators and confounders in the first stage regression. All models also include Weimar state fixed effects (interpolated based on the centroids of contemporary Gemeinden) in both stages. ${ }^{*} \mathrm{p}<0.05 ;{ }^{* *} \mathrm{p}<0.01$ 
Figure SI4.1: The controlled direct effect of camp proximity on outgroup intolerance, immigrant resentment, and support for far-right parties (EVS), with alternative methods to interpolate Weimar states from contemporary Kreise

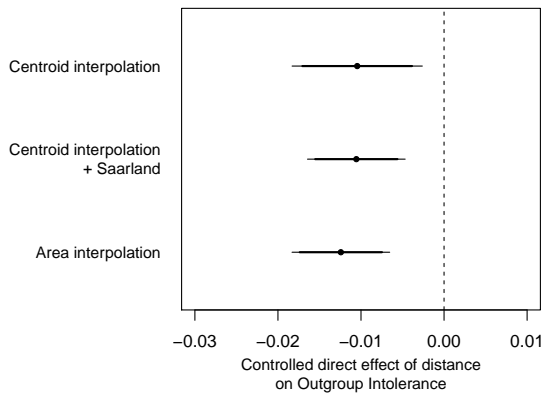

(a) Out-group Intolerance

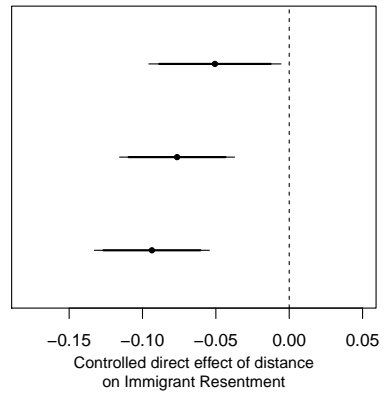

(b) Immigrant Resentment

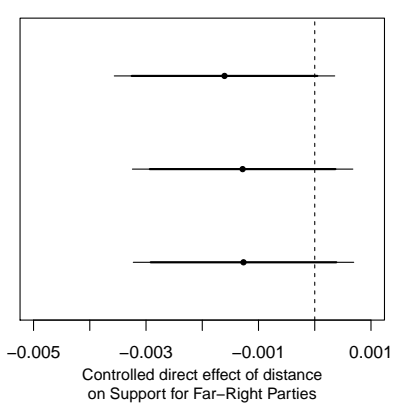

(c) Far-Right Support

Note: Plots depict estimates and 95/90\% confidence intervals from the sequential g-estimator for the controlled direct effects of distance to camps on contemporary attitudes (described in each panel). Each estimate corresponds to a different model based on alternative methods to match contemporary districts with Weimar-era states. 
Figure SI4.2: Effects of camp proximity on out-group intolerance, immigrant resentment, and support for far-right parties (EVS), accounting for state-level heterogeneity

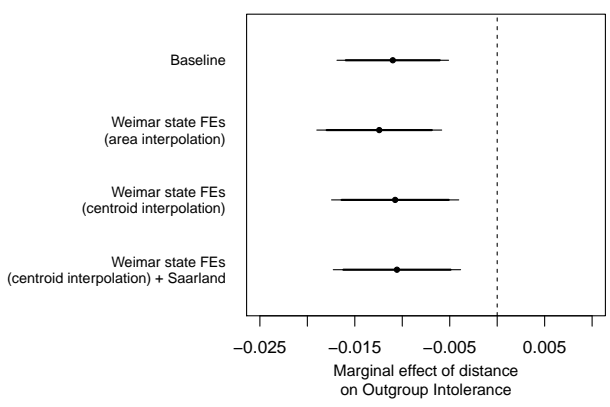

(a) Out-group Intolerance

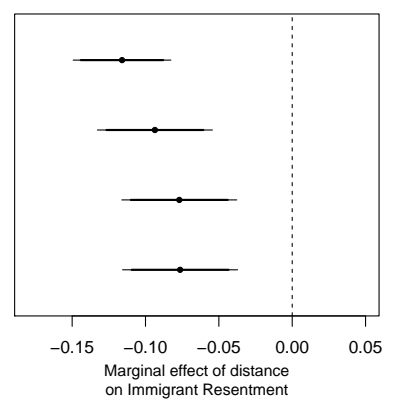

(b) Immigrant Resentment

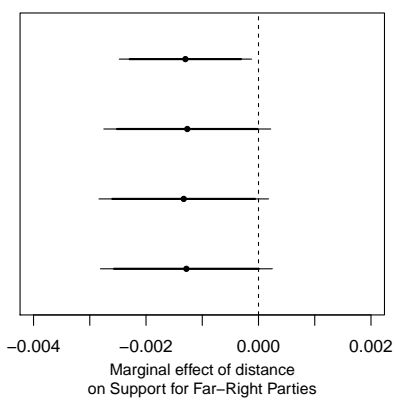

(c) Far-Right Support

Note: Plots depict estimates and 95/90\% confidence intervals from OLS models for the effects of distance to camps on contemporary attitudes (described in each panel label). Each estimate derives from a different model specification, described on the $y$-axis. The baseline specification corresponds to the results reported in Table 2 (Models 1, 3, and 5) in Homola et al. (2020). 


\section{SI5: Additional analyses using one mediating variable}

In our original analysis (Homola et al. 2020) and the models we report in the main text, we include multiple mediating variables. This could be stretching the limits of the g-estimation approach. While the approach allows for multiple mediators (see Blackwell et al. 2019), many existing applications only use one mediating variable (Acharya et al. 2016a; 2016b; Robins et al 1992; Vansteelandt 2009). As a robustness check, we therefore replicated all models using only one contemporary variable as mediator and specifying the other variables as confounders. More specifically, in Figure SI5.1 we show that our electoral analysis is robust to specifying only the share of foreigners as a mediator. In Figure SI5.2 we similarly show that our EVS analysis is robust to only specifying respondents' self-reported ideology as the mediator. In both analyses, (i) all other contemporary variables are specified as confounders, and (ii) the results are substantively the same when we use another contemporary variable as mediator and the remaining ones are introduced as confounders. 
Figure SI5.1: The controlled direct effect of camp proximity on support for radical right parties in 2017, accounting for state-level heterogeneity and using the share of foreigners as the contemporary mediator

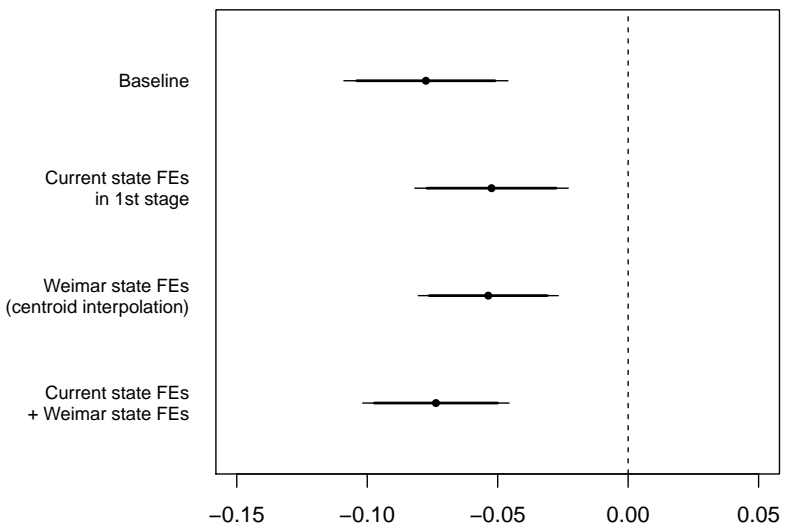

(a) AfD full

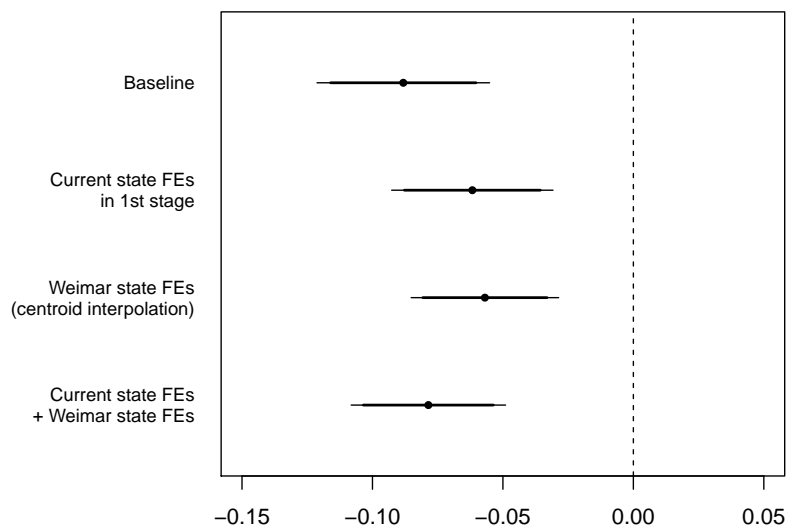

(c) AfD+NPD, full

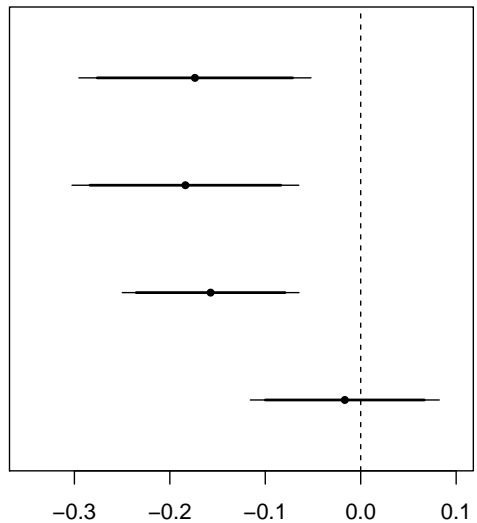

(b) AfD, $70 \mathrm{~km}$

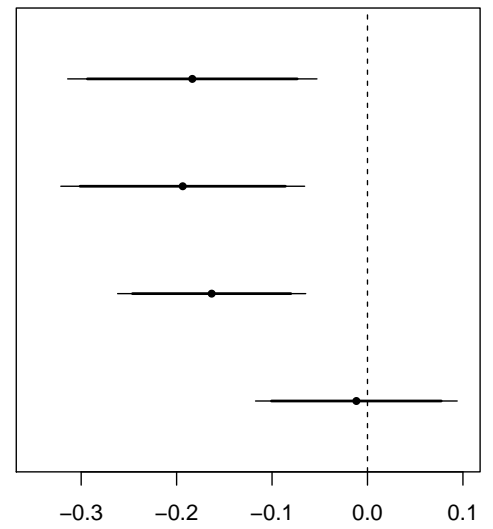

(d) AfD $+\mathrm{NPD}, 70 \mathrm{~km}$

Note: Plots depict estimates and 95/90\% confidence intervals from the sequential g-estimator for the controlled direct effects of distance to camps on support for radical right parties in 2017 (described in each panel label) using only the share of foreigners as a contemporary mediator. Each estimate corresponds to a different model specification, described on the $y$-axis. 
Figure SI5.2: The controlled direct effect of camp proximity on outgroup intolerance, immigrant resentment, and support for far-right parties (EVS), accounting for state-level heterogeneity and using ideology as the contemporary mediator

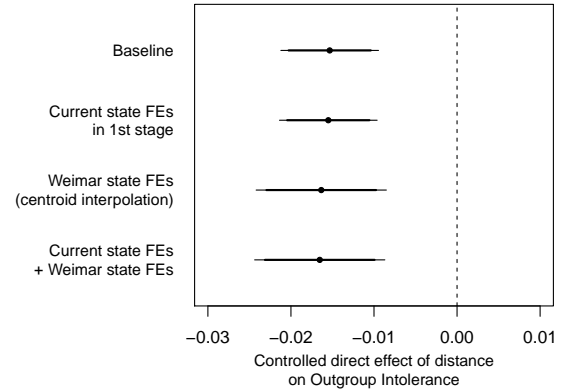

(a) Outgroup Intolerance

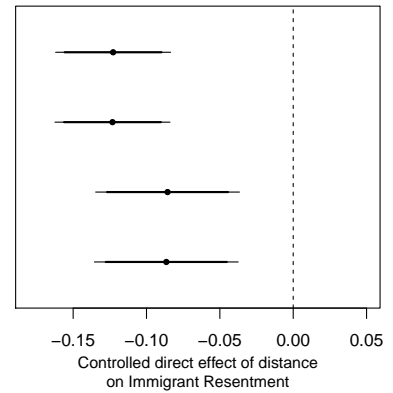

(b) Immigrant Resentment

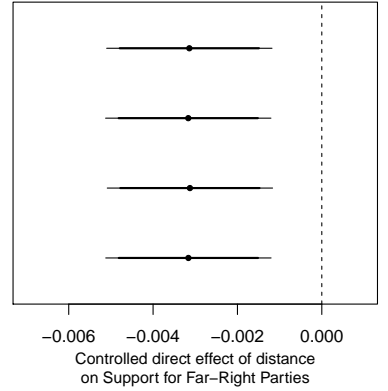

(c) Far-Right Support

Note: Plots depict estimates and 95/90\% confidence intervals from the sequential g-estimator for the controlled direct effects of distance to camps on contemporary attitudes (described in each panel label) using only the respondents' self-reported ideology as a contemporary mediator. Each estimate corresponds to a different model specification, described on the $y$-axis. 


\section{SI6: Prussian provinces: discussion and additional analyses}

Among their other models, PGZ also include an analysis with Weimar-era fixed effects. Although the authors do not describe their exact interpolation strategy and use a map from 1925, the results reported are substantively similar to those we report here but inconsistent with PGZ's own argument. They then further split the analyses, treating Prussian internal provinces as separate states, which renders the effects of camp proximity unreliable. In this section, we take a closer look at these analyses and point out two concerns: (a) the decision to split Prussia into provinces appears arbitrary, atheoretical, and leads to an underpowered analysis, and (b) PGZ's coding of states and provinces features a clear mistake. We then proceed to show that when we include province-level fixed effects in properly specified models of our electoral analysis, our main findings remain unchanged.

1. Arbitrary decision to include Prussian provinces: PGZ's main argument for the inclusion of Prussian province fixed effects is the following: "Prussia's own inherent regional heterogeneity suggest[s] that we should investigate the provincial structure of Prussia as well" (p. 30). We will discuss the point of within-Prussia heterogeneity below, but regardless of whether there was serious heterogeneity or not, the decision to include fixed effects for Weimar-era Germany's states and Prussia's provinces in the same model specification seems arbitrary. Such a setup is equivalent to including state fixed effects for some US states, and county (or congressional district) fixed effects for others. Although California might be more heterogeneous than Rhode Island, we are not aware that this is a common empirical approach.

2. Atheoretical approach: PGZ claim that within-Prussia heterogeneity necessitates the inclusion of province fixed effects. As an example, they discuss a failed Reichsreform which "planned to divide Prussia into several sub-states" (p. 30). We actually believe this example makes an argument against the inclusion of province fixed effects. The reform failed because Prussia did not want to lose the influence it had over the federal 
government (as the largest state). It was the opposition of the Prussian state as a whole - not of specific provinces - that blocked this reform (Schulz 1963). As such, the failed reform is an example of Prussian unity, not division.

Moreover, Holborn (1956: 335) explicitly describes that in "Prussia itself [...] no strong signs could be found that the provinces wished to become states." In fact, the Weimar constitution included a provision for the possible secession of individual provinces through plebiscite. As far as we can tell, this instrument was used only once, in Upper Silesia, where over 90\% voted to remain part of Prussia in 1922 (HertzEichenrode 1969; Schattkowsky 1994). Another attempt to schedule a plebiscite in Hanover in 1924 failed because there was not enough interest among voters (Funk 2010; Heimann 2011). This is in line with other accounts that emphasize the relevance and strength of Prussia as a whole (Orlow 1991). In other words, these historical accounts provide little evidence to support strong concerns regarding Prussia's own inherent regional heterogeneity.

We believe this discussion highlights once again the importance of having well articulated theoretical arguments to motivate one's modeling choices. For instance, if one is interested in capturing differences in school curricula that are determined at the state level, state-level fixed effects should be included. If instead one is interested in capturing administrative differences that vary at the substate level, then the analysis should include fixed effects at the level of the administrative region below the state. In the case of Weimar Germany, this would imply using provinces in Prussia, but also including fixed effects for Regierungsbezirke in the case of Bavaria for example. Choosing one level in one state and another in the remaining states is a decision that seems difficult to motivate theoretically.

3. Underpowered analysis: As we discuss in the main text, the introduction of statelevel fixed effects leads to a severely underpowered analyses. This issue becomes even more problematic when PGZ decide to introduce Prussia province-level fixed effects 
on top of state-level fixed effects. Using this setup for the EVS data, the number of observations by state/province ranges from only 11 to 267 (with a median of 60.5) in the OLS specifications, and from 1 to 175 (with a median of 36.5) in the g-estimator specifications. Table SI4.3 describes the number of observations and sampling units by state/province. As a consequence, variation in the main predictor of interest camp proximity - is extremely limited within each state/province. In the g-estimator specification, respondents from nine of 24 states/provinces now feature the same camp distance measure. Given the reliance on within-state/province variation, these nine states/provinces no longer contribute anything to the empirical analysis. It is therefore not surprising that the estimates PGZ present fail to reach statistical reliability at conventional levels.

4. Coding error: PGZ's coding of states and provinces treats the Weimar state of MecklenburgSchwerin and the Prussian province of Saxony as the same regional unit. We discuss this issue in more detail in SI 8.

5. Prussian provinces and electoral data: Despite our concerns regarding PGZ's arbitrary and atheoretical inclusion of province fixed effects, we decided to replicate our electoral analysis (where the power issue is less concerning) while accounting for Prussia's provinces. More specifically, we follow the analysis in the main text and replicate Table 4 in HPT while including (1) contemporary state-level fixed effects in the first stage of the g-estimator, (2) Weimar-era state-level and Prussian province-level fixed effects in both stages of the g-estimator, and (3) both contemporary states and Weimar-era states and Prussian provinces. The results in Figure SI6.1 show that our main conclusions are robust to this hybrid approach of using fixed effects at the province level within Prussia and at the state level for the rest of the country. Across the different specifications, we see that the effect of distance is always negative and statistically reliable at conventional levels. The results provide further evidence for our theoretical 
claims and for the idea that the use of province-level fixed effects is inappropriate using survey data where it leads to underpowered analysis. 
Figure SI6.1: The controlled direct effect of camp proximity on support for radical right parties in 2017, accounting for state-level and Prussian province-level heterogeneity

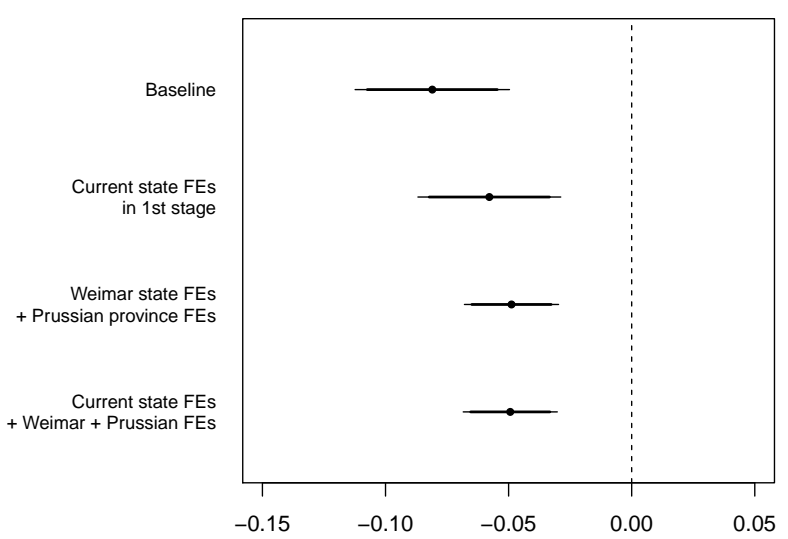

(a) AfD, full sample

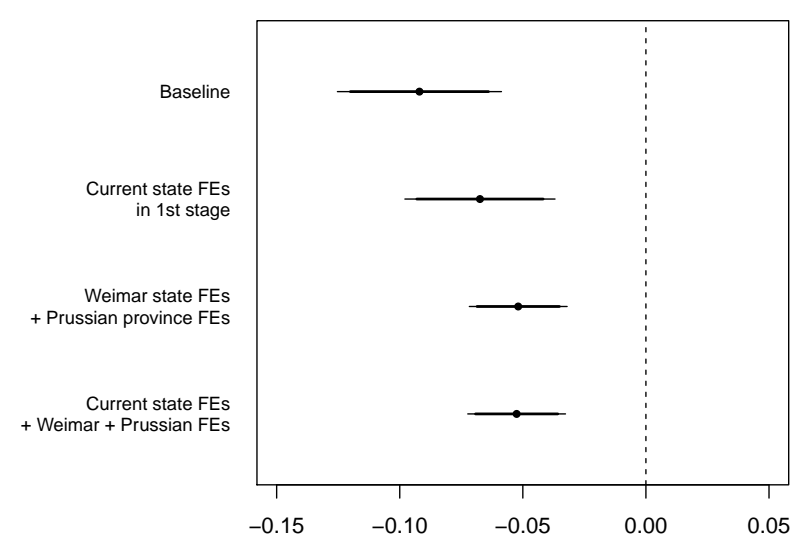

(c) AfD $+\mathrm{NPD}$, full sample

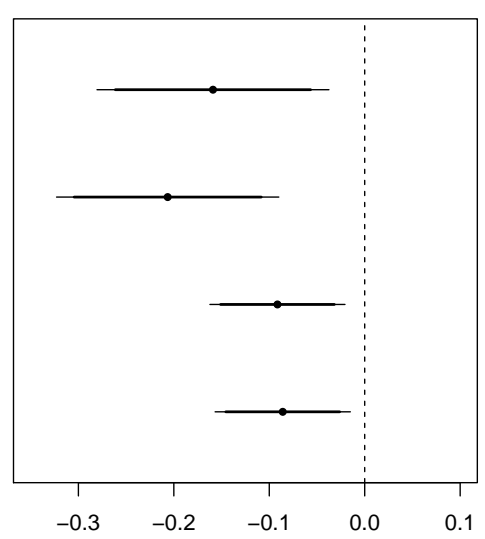

(b) AfD, $70 \mathrm{~km}$ radius

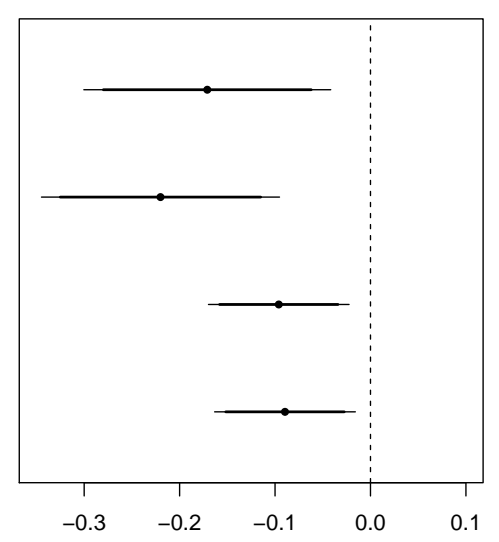

(d) $\mathrm{AfD}+\mathrm{NPD}, 70 \mathrm{~km}$ radius

Note: Plots depict estimates and 95/90\% confidence intervals from the sequential g-estimator for the controlled direct effects of distance to camps on support for radical right parties in 2017 (described in each panel label). Each estimate corresponds to a different model specification, described on the $y$-axis. The baseline specification corresponds to the results reported in Table 4 in Homola et al. (2020). 


\section{SI7: Noise simulations}

In order to further address the potential issue of spatial correlation, we follow Kelly's (2019) recommendation and generate artificial noise variables to test the robustness of our main results. More specifically, we replace our geographic variable (Distance) with spatially correlated noise. Following Kelly, this spatial noise is drawn from a multivariate normal distribution using a variance-covariance matrix based on the Matern function. For the Matern function, we set the variance and shape parameters to be 1. For the crucially important correlation range, we follow Kelly's recommendations for the analysis of German data and present our results for a correlation range of 3 degrees and a correlation range of 5 degrees. ${ }^{1}$

For each observation, we use this setup to draw 1,000 iterations of spatial noise. We then run 1,000 regressions replicating our g-estimation models, where the spatial noise replaces the Distance variable. ${ }^{2}$ For every regression, we store the p-value of the spatial noise variable. The distribution of these p-values is then plotted in Figures SI7.1-SI7.4, along with a red vertical line illustrating the p-values from the original regressions. Across the different datasets and outcome variables, spatial noise very rarely outperforms our Distance variable in terms of explanatory power. Spatial correlation does not appear to be an important threat to inference in this context.

\footnotetext{
${ }^{1}$ See Fouka and Voth (2020) for another recent implementation of this approach.

${ }^{2}$ Given the computationally intensive nature of this method, we report regular (i.e., non-bootstrapped) standard errors for these models.
} 
Figure SI7.1: The controlled direct effect of spatial noise on support for radical right parties in 2017 (correlation range of 3 degrees)

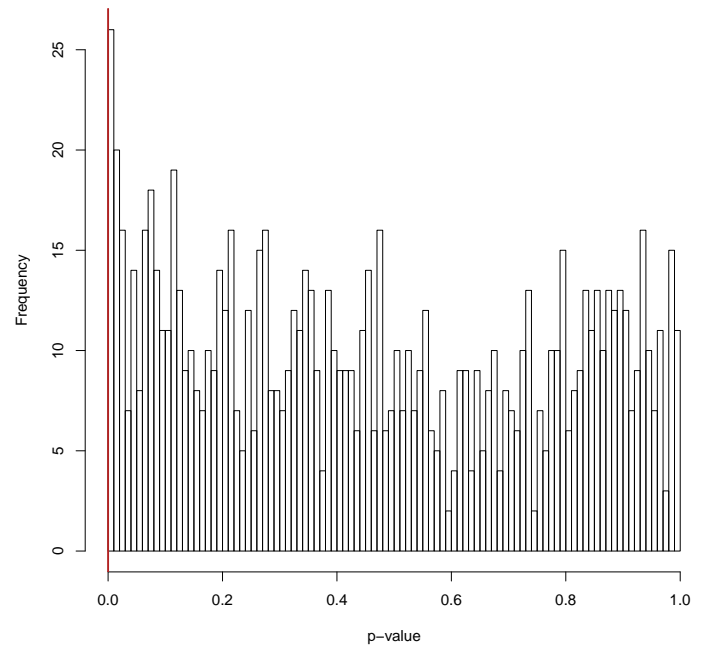

(a) AfD, full sample

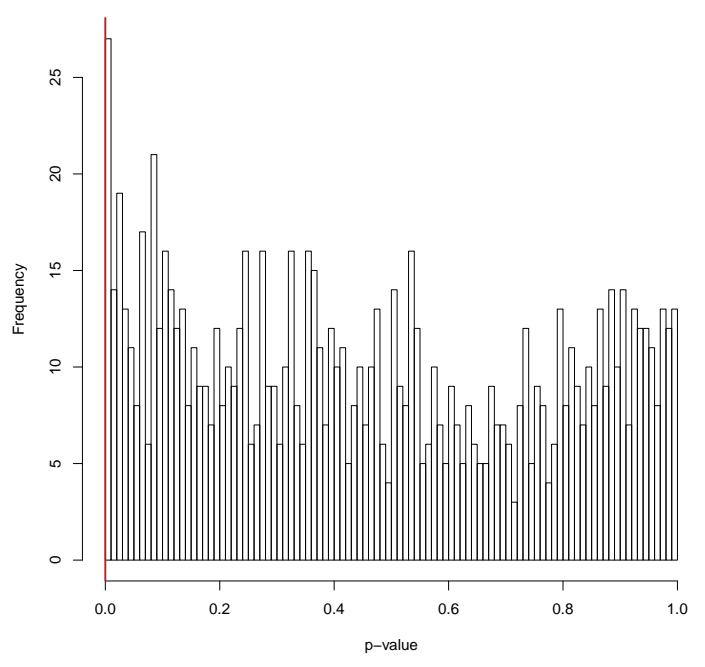

(c) AfD $+\mathrm{NPD}$, full sample

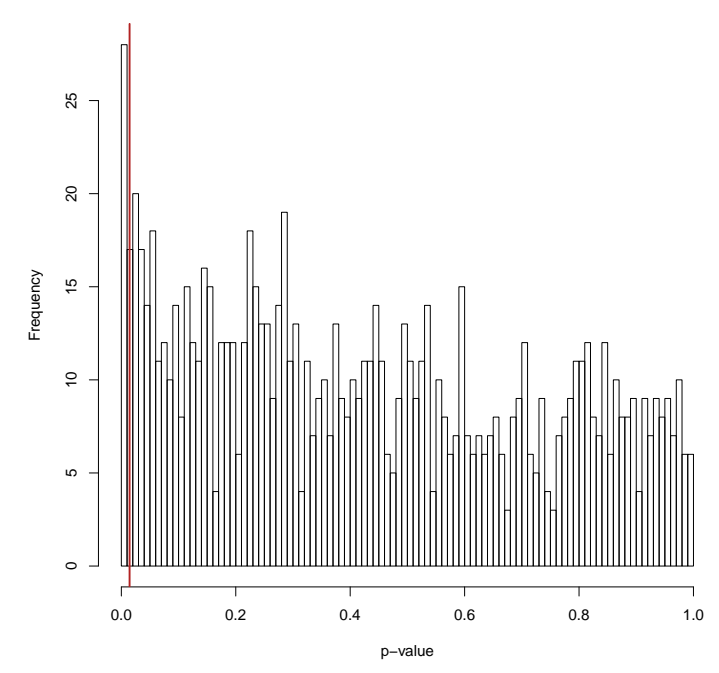

(b) AfD, $70 \mathrm{~km}$ radius

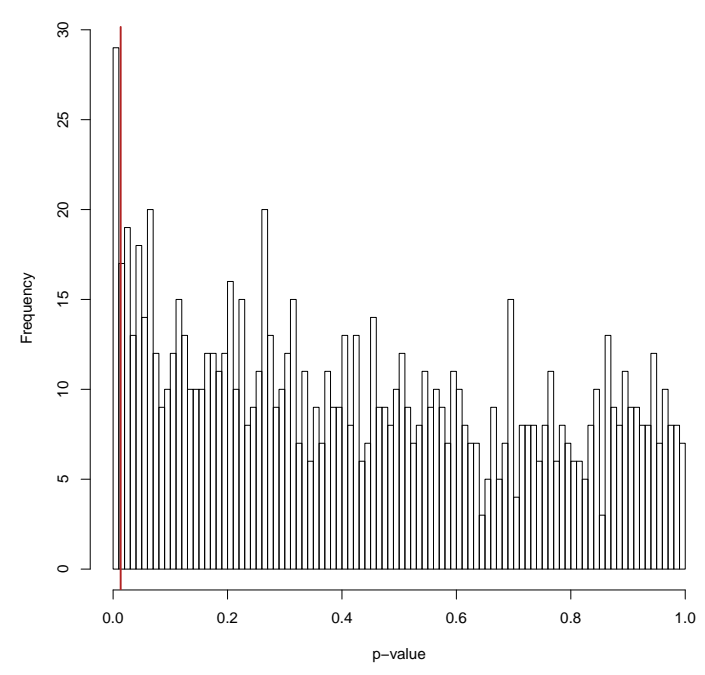

(d) $\mathrm{AfD}+\mathrm{NPD}, 70 \mathrm{~km}$ radius

Note: Plots show the distribution of p-values resulting from 1,000 simulations of the sequential g-estimator for the controlled direct effects of distance to camps on support for radical right parties in 2017 (described in each panel label). In each iteration, Distance has been replaced by simulated spatially correlated noise according to the Matern function, with a variance and shape of 1 and a correlation range of 3 degrees, following Kelly (2019) and Fouka and Voth (2020). The red vertical line indicates the p-value from the original model specification. The explanatory power of spatial noise is higher than that of our Distance variable $0.0 \%$ (panel a), 3.8\% (panel b), $0.0 \%$ (panel c), and 3.4\% (panel d) of the time respectively. 
Figure SI7.2: The controlled direct effect of spatial noise on support for radical right parties in 2017 (correlation range of 5 degrees)

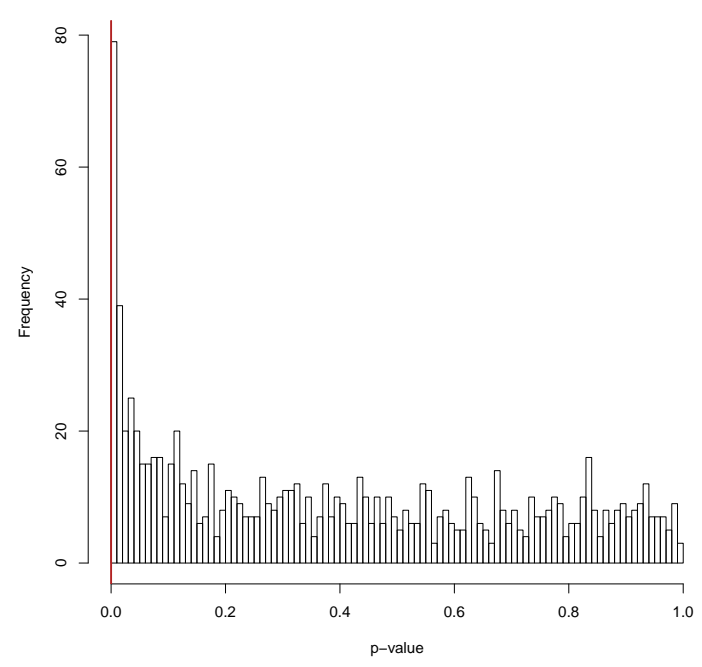

(a) AfD, full sample

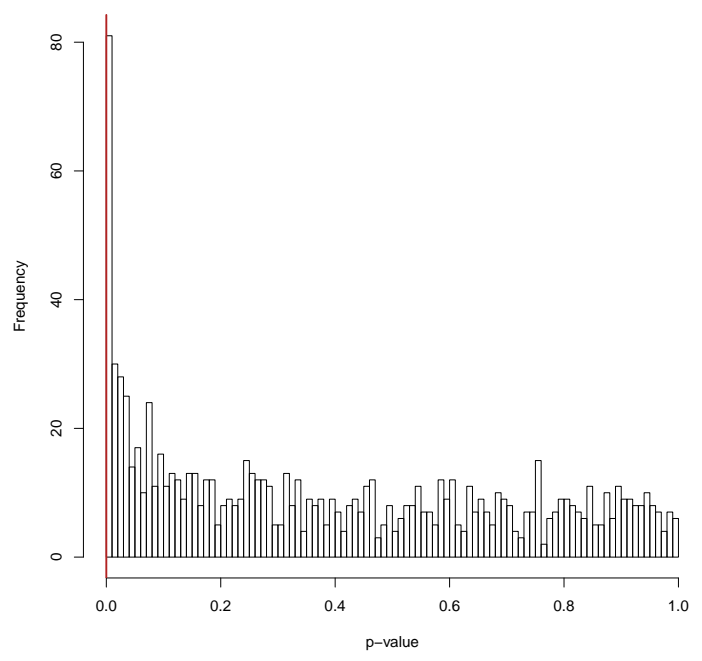

(c) AfD $+\mathrm{NPD}$, full sample

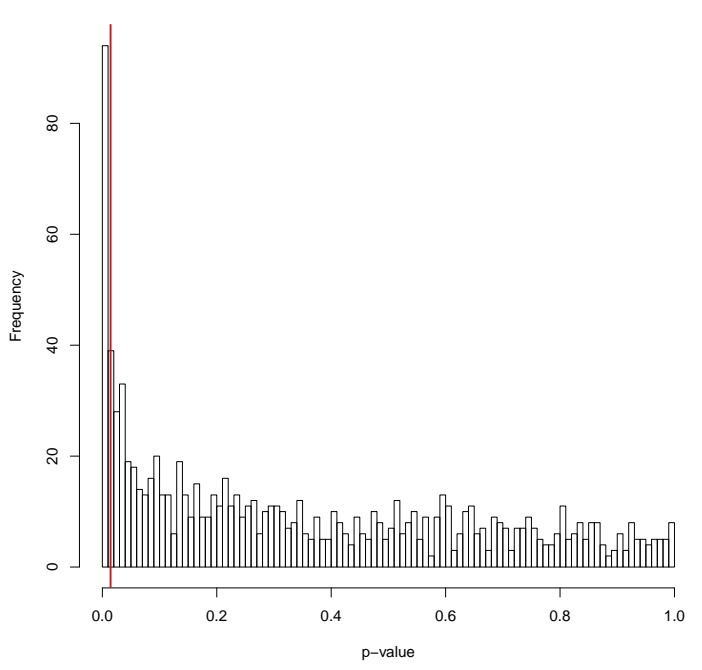

(b) AfD, $70 \mathrm{~km}$ radius

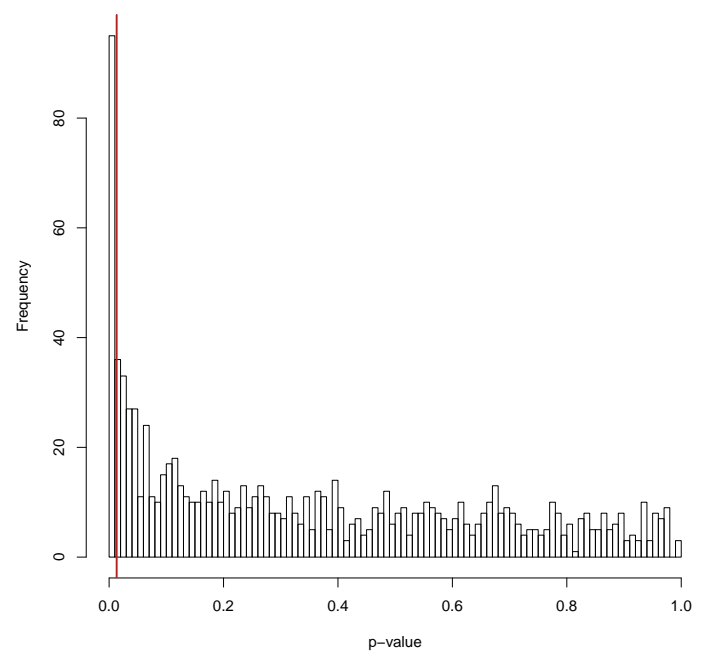

(d) $\mathrm{AfD}+\mathrm{NPD}, 70 \mathrm{~km}$ radius

Note: Plots show the distribution of p-values resulting from 1,000 simulations of the sequential g-estimator for the controlled direct effects of distance to camps on support for radical right parties in 2017 (described in each panel label). In each iteration, Distance has been replaced by simulated spatially correlated noise according to the Matern function, with a variance and shape of 1 and a correlation range of 5 degrees, following Kelly (2019) and Fouka and Voth (2020). The red vertical line indicates the p-value from the original model specification. The explanatory power of spatial noise is higher than that of our Distance variable $0.0 \%$ (panel a), $11.2 \%$ (panel b), $0.0 \%$ (panel c), and $11.1 \%$ (panel d) of the time respectively. 
Figure SI7.3: The controlled direct effect of spatial noise on outgroup intolerance, immigrant resentment, and support for far-right parties (correlation range of 3 degrees)

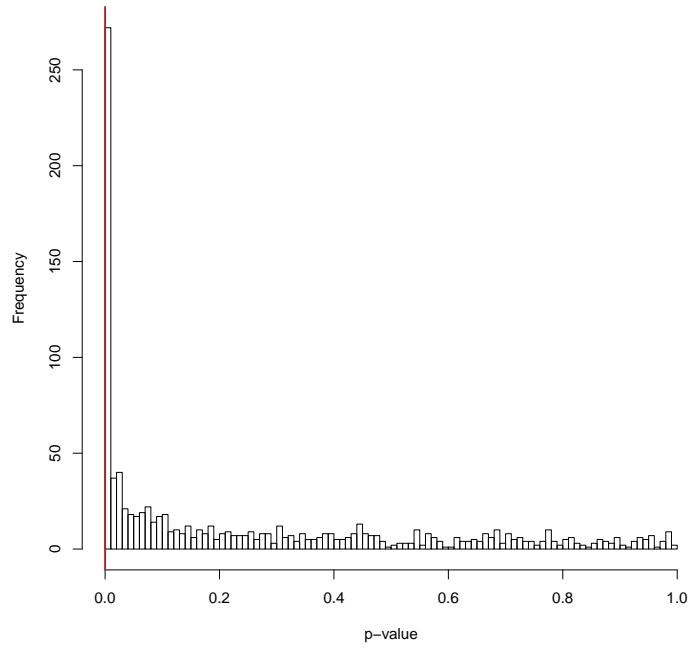

(a) Outgroup Intolerance

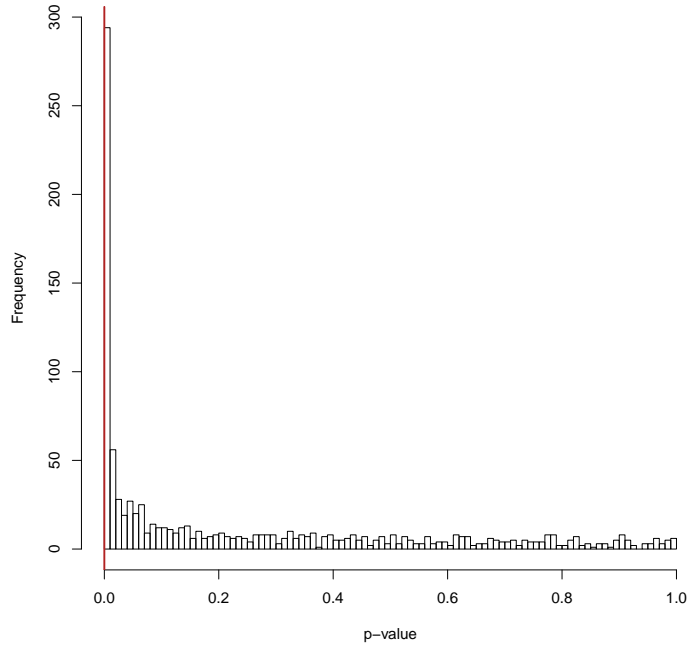

(b) Immigrant Resentment

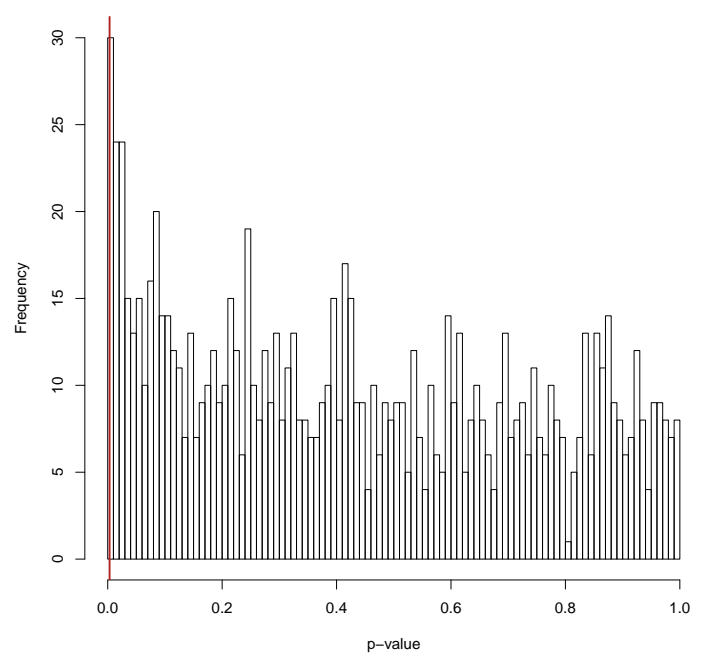

(c) Far-Right Support

Note: Plots show the distribution of p-values resulting from 1,000 simulations of the sequential g-estimator for the controlled direct effects of distance to camps on contemporary attitudes (described in each panel label). In each iteration, Distance has been replaced by simulated spatially correlated noise according to the Matern function, with a variance and shape of 1 and a correlation range of 3 degrees, following Kelly (2019) and Fouka and Voth (2020). The red vertical line indicates the p-value from the original model specification. The explanatory power of spatial noise is higher than that of our Distance variable $5.1 \%$ (panel a), $0.4 \%$ (panel b), and 1.1\% (panel c) of the time respectively. 
Figure SI7.4: The controlled direct effect of spatial noise on outgroup intolerance, immigrant resentment, and support for far-right parties (correlation range of 5 degrees)

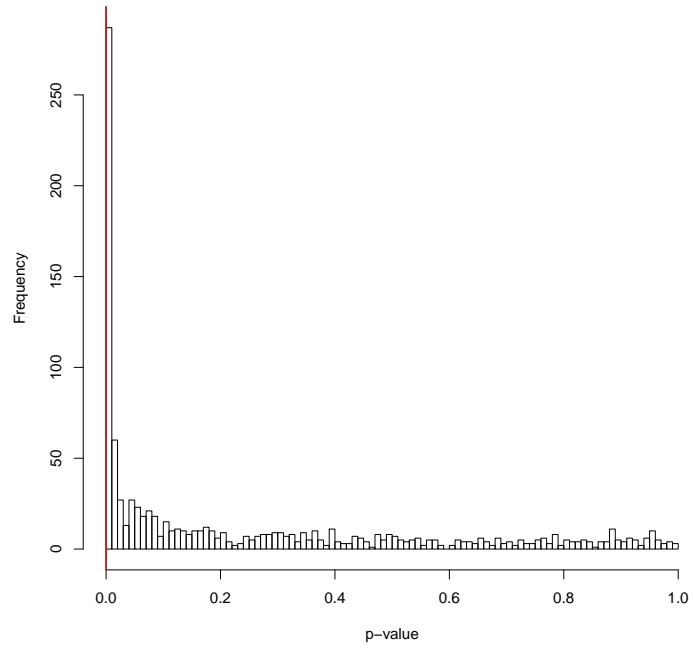

(a) Outgroup Intolerance

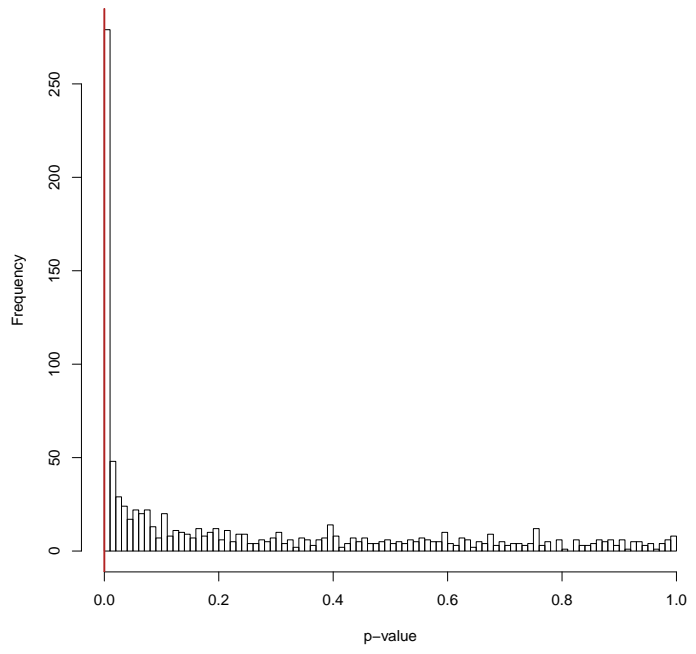

(b) Immigrant Resentment

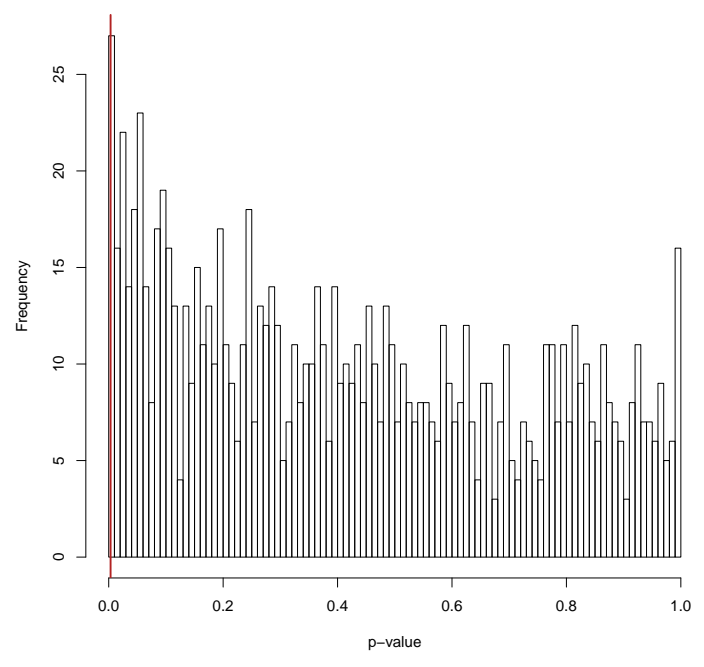

(c) Far-Right Support

Note: Plots show the distribution of p-values resulting from 1,000 simulations of the sequential g-estimator for the controlled direct effects of distance to camps on contemporary attitudes (described in each panel label). In each iteration, Distance has been replaced by simulated spatially correlated noise according to the Matern function, with a variance and shape of 1 and a correlation range of 5 degrees, following Kelly (2019) and Fouka and Voth (2020). The red vertical line indicates the p-value from the original model specification. The explanatory power of spatial noise is higher than that of our Distance variable $4.5 \%$ (panel a), $0.9 \%$ (panel b), and 1.1\% (panel c) of the time respectively. 


\section{SI8: Inconsistencies in PGZ}

This section briefly lists a number of inconsistencies in PGZ. More specifically, points 1-3 discuss instances where PGZ's discussion of existing work is inconsistent with the original sources. Points 4-5 discuss inconsistencies in PGZ's data and analysis. We hope that this discussion will help readers avoid confusion and allow them to better follow PGZ's criticism of HPT and our discussion of both studies.

1. Misrepresentation of key findings: In their conclusion, PGZ (p. 36-37) state that HPT argue that (a) "Germany's considerable, wide-reaching and deep educational efforts to 'counteract the legacy effect' of the Holocaust have not been successful," (b) the way to "'break[ing] the detrimental legacy effects' is not in education," and (c) the way to overcome legacy effects instead lies in "erasure, tearing down the camps and freeing Germans from this optical tether." HPT actually state the exact opposite. We write (a) "our main findings do not imply that the national re-education campaigns failed," (b) that "efforts to re-educate the population may not be in vain," and (c) that "Holocaust-related education promoted by these camps may offer a path to mitigate the effects of cognitive dissonance produced during the Nazi era" (HPT, p. 14). HPT discuss these points in a section of the empirical analysis (and corresponding parts of the Appendix) that deals explicitly with the educational effects of camps.

2. Discussion and replication of wrong model specification: In their analysis of the EVS and ALLBUS survey data, HPT always present two models per outcome variable: (1) a simple OLS regression that only includes the distance measure and pre-treatment covariates, and (2) the second step of the g-estimator to also account for contemporary (post-treatment) variables. In their main results table, PGZ attempt to replicate our two models and then extend them using state fixed effects. Unfortunately, the second model they replicate and then extend (PGZ Table 1, Columns 5-6) represents a specification that does not appear in the HPT main text. PGZ's replication file reveals 
that these models represent the first stage of the g-estimator, not the appropriate second stage. The results of these models suffer from post-treatment bias by design and cannot be interpreted in any meaningful way. ${ }^{3}$

3. Misrepresentation of other work: In their reanalysis of HPT's electoral data, PGZ (p. 31-34) find that areas farther away from camps tend to vote more right-wing. They state that these "results are comparable to Hoerner et al.'s (2019)" and discuss that "it is reassuring that our reanalysis of HPT's analysis of ten camps yields parallel findings to Hoerner et al.'s study of all Nazi concentration camps." Hoerner et al. actually find the exact opposite; their abstract states: "We find that proximity to a former concentration camp is associated with a higher vote share of such parties." 4

4. Inconsistencies in the implementation of the g-estimator: There are repeated inconsistencies in PGZ's implementation of the g-estimator. First, the labeling of the first and second stage in their replication file is often wrong. This might explain why they report and replicate the wrong model specifications we discuss in point \#2 above. Second, they make mistakes in their estimation strategy. While the coefficient estimates PGZ report for their g-estimator models (Table 1, Column 8) come from a second stage model that contains state fixed effects, these fixed effects are not present in the second stage when PGZ calculate the corresponding bootstrapped standard errors. In other words, the standard errors they present come from a different model specification than the coefficient estimates they report and are therefore incorrect.

5. Coding error: In their analysis using hybrid fixed effects - Weimar-era states and

\footnotetext{
${ }^{3}$ The purpose of the first stage is to inform the correction that occurs in the second stage. Given this, HPT follow existing conventions (e.g., Acharya et al. 2016a) and report the first stage results only in the online appendix without trying to interpret them.

${ }^{4}$ To be more specific, PGZ state that their findings are in line with the results in Hoerner et al. (2019), Table 1, Model 5. Table 1 has a total of 8 Models, and Hoerner et al. (2019, p. 7) describe the main takeaway as follows: "the vote share of radical-right parties is on average higher in municipalities in close proximity to a former camp." Model 5 does indeed feature a positive (and unreliable) coefficient estimate for distance that is very close to zero. However, the main conclusions of Hoerner et al. draw on the totality of their evidence rather than on any single model and clearly contradict PGZ's finding.
} 
Prussia provinces - PGZ treat the Weimar state of Mecklenburg-Schwerin and the Prussian province of Saxony as the same regional unit. In other words, respondents from both areas are treated as living in the same state/province although one is a province of Prussia and the other is its own state. PGZ do not provide a source for their map of Weimar Germany and also do not describe their exact interpolation strategy, but our analysis of their replication code suggests that this coding error arises because they choose to assign the same province/state code (2000) to the Prussian province of Saxony that is already used by the state of Mecklenburg-Schwerin. Figure SI8.1 illustrates the error. We provide a more general and detailed discussion of the provincelevel analysis in SI 6.

Figure SI8.1: Weimar states and Prussian provinces in 1932

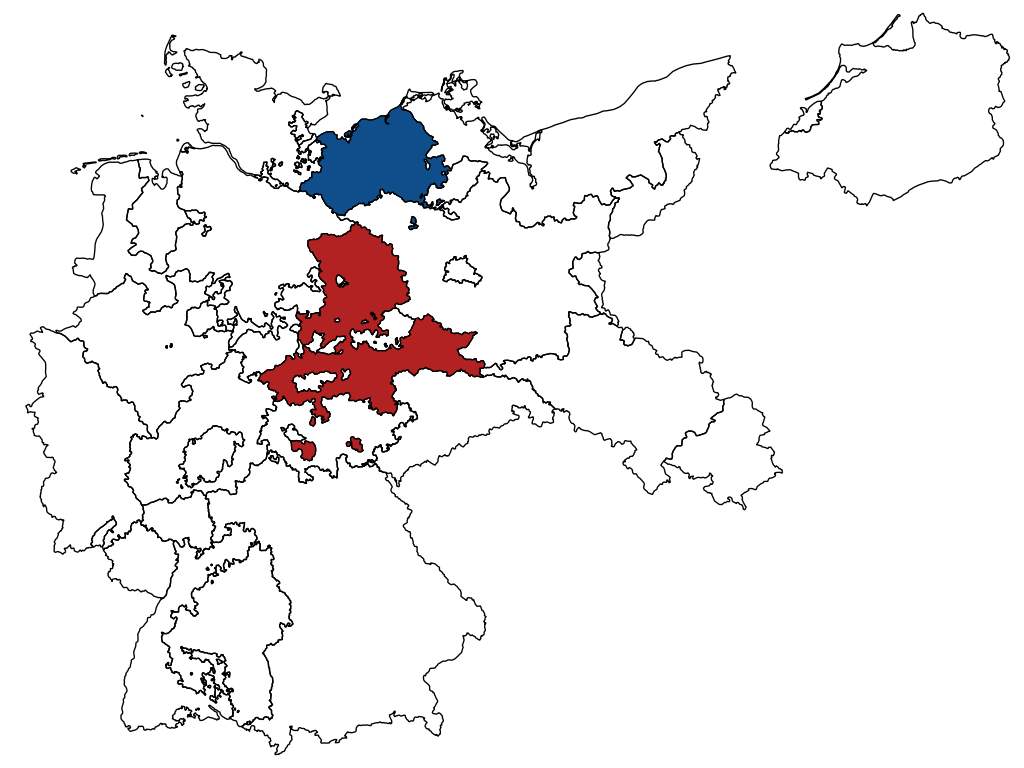

Note: The map shows Weimar states and Prussian provinces in 1932. The Weimar state of MecklenburgSchwerin is highlighted in blue. The Prussian province of Saxony is highlighted in red. The analysis in PGZ treats both as the same regional unit. 


\section{SI9: Inappropriateness of Moran statistic for survey data}

PGZ follow Kelly's (2019) recommendation and compute Moran's autocorrelation index for the association between distance and each of the outcome variables in the EVS analysis. However, there is one important difference between the studies Kelly analyzes and the survey data used in HPT: the unit of analysis. Almost all of the studies Kelly examines use population data at a certain level of aggregation (i.e., countries, states, cities). Only two of the 27 studies feature individual-level data that are comparable to our surveys. Kelly (2019: 17) explicitly does not compute Moran test statistics for these studies: "For analyses using large numbers of people at each site (Dell 2010; Nunn and Wantchekon 2011) Moran statistics are not computed."

The reason for this is the clustered data structure. Both EVS and ALLBUS interview multiple respondents in a specific number of primary sampling units. In both cases, the sampling procedure starts from a a random sample of German municipalities (while oversampling municipalities in the East). Within each selected municipality, a new random sample is drawn to select individual respondents (ALLBUS 2017; EVS 2010). We then assigned respondents to their respective Kreis and calculate the distance measure. In short, the data generating process leads to geographic clustering that does not occur in the papers Kelly reanalyzes. 


\section{SI10: References}

Acharya, Avidit, Matthew Blackwell, and Maya Sen. 2016a. "The political legacy of American slavery." The Journal of Politics 78: 621-641.

Acharya, Avidit, Matthew Blackwell, and Maya Sen. 2016b. "Explaining causal findings without bias: Detecting and assessing direct effects." American Political Science Review 110: 512-529.

ALLBUS. 2017. "ALLBUS 2016 - Variable Report." GESIS-Variable Reports Nr. 2017/10. DOI: $10.4232 / 1.12796$

Blackwell, Matthew, Avidit Acharya, Maya Sen, Shiro Kuriwaki, and Jacob Brown. 2019. "DirectEffects: Estimating Controlled Direct Effects for Explaining Causal Findings." $\mathrm{R}$ package version 0.2 . https://cran.r-project.org/package=DirectEffects

Dell, Melissa. 2010. "The persistent effects of Peru's mining mita." Econometrica 78: 1863-1903.

EVS. 2010. "EVS 2008 Method Report." GESIS-Technical Reports 2010/17. Available at: http://www . europeanvaluesstudy.eu/.

Fouka, Vasiliki, and Hans-Joachim Voth. 2020. "Collective Remembrance and Private Choice: German-Greek Conflict and Consumer Behavior in Times of Crisis." URL: https://vfouka.people.stanford.edu/sites/g/files/sbiybj4871/f/collective_ memory_greece_0.pdf

Funk, Albert. 2010. Kleine Geschichte des Föderalismus: vom Fürstenbund zur Bundesrepublik. Paderborn: Ferdinand Schöningh.

Heimann, Siegfried. 2011. Der Preußische Landtag 1899-1947: eine politische Geschichte. Berlin: Links.

Hertz-Eichenrode, Dieter. 1969. Politik und Landwirtschaft in Ostpreußen 1919-1930: Untersuchung eines Strukturproblems in der Weimarer Republik. Köln, Opladen: Westdeutscher Verlag.

Hoerner, Julian M., Alexander Jaax, and Toni Rodon. 2019. "The Long-Term Impact of the 
Location of Concentration Camps on Radical-Right Voting in Germany." Research G Politics. DOI: $10.1177 / 2053168019891376$

Holborn, Hajo. 1956. "Prussia and the Weimar Republic." Social Research 23: 331-342.

Homola, Jonathan, Miguel M. Pereira, and Margit Tavits. 2020. "Legacies of the Third Reich: Concentration Camps and Out-Group Intolerance." American Political Science Review 114: 573-590.

Kelly, Morgan. 2019. "The Standard Errors of Persistence." June 3. Available at SSRN. DOI: $10.2139 /$ ssrn. 3398303

Nunn, Nathan, and Leonard Wantchekon. 2011. "The slave trade and the origins of mistrust in Africa." American Economic Review 101: 3221-3252.

Orlow, Dietrich. 1991. Weimar Prussia, 1925-1933: The Illusion of Strength. Pittsburgh: University of Pittsburgh Press.

Robins, James M., Donald Blevins, Grant Ritter, and Michael Wulfsohn. 1992. "Gestimation of the effect of prophylaxis therapy for Pneumocystis carinii pneumonia on the survival of AIDS patients." Epidemiology 3: 319-336.

Schattkowsky, Ralph. 1994. "Separatism in the Eastern provinces of the German Reich at the end of the First World War." Journal of Contemporary History 29: 305-324.

Schulz, Gerhard. 1963. Zwischen Demokratie und Diktatur: Verfassungspolitik und Reichsreform in der Weimarer Republik. Band 1. Die Periode der Konsolidierung und der Revision des Bismarckschen Reichsaufbaus 1919-1930. Berlin: de Gruyter.

Vansteelandt, Sijn. 2009. "Estimating Direct Effects in Cohort and Case-Control Studies." Epidemiology 20: 851-860. 